\title{
A Novel Reciprocating Tribometer for Friction and Wear Measurements with High Contact Pressure and Large Area Contact Configurations
}

\author{
Kim Berglund*(D), Maria Rodiouchkina (D), Jens Hardell, Kalle Kalliorinne and Jens Johansson \\ Division of Machine Elements, Luleå University of Technology, SE 97187 Luleå, Sweden; \\ maria.rodiouchkina@ltu.se (M.R.); jens.hardell@ltu.se (J.H.); kalle.kalliorinne@ltu.se (K.K.); \\ jensjohansson3000@gmail.com (J.J.) \\ * Correspondence: kim.berglund@ltu.se
}

Citation: Berglund, K.;

Rodiouchkina, M.; Hardell, J.;

Kalliorinne, K.; Johansson, J. A Novel Reciprocating Tribometer for Friction and Wear Measurements with High Contact Pressure and Large Area Contact Configurations. Lubricants 2021, 9, 123. https://doi.org/ 10.3390/lubricants9120123

Received: 29 October 2021

Accepted: 14 December 2021

Published: 17 December 2021

Publisher's Note: MDPI stays neutral with regard to jurisdictional claims in published maps and institutional affiliations.

\begin{abstract}
There are many moving machine assemblies with conformal tribological contacts at very high contact pressures, e.g., sliding bearings, propeller shaft bearings and machine guideways. Furthermore, applications such as trunnion and guide vane bearing in Kaplan turbines have very low sliding speeds and oscillatory types of motion. Although there is a vast selection of tribology test rigs available, there is still a lack of test equipment to perform friction and wear tests under high contact pressure, reciprocatory sliding and large area contact. The aim of this work is thus to develop a novel reciprocating tribometer and test method that enables friction and wear tests under low-speed reciprocatory sliding with contact pressures up to $90 \mathrm{MPa}$ in a flat-on-flat contact configuration. First, a thorough description of the test rig design is given. Secondly, the influence of contact pressure and stroke length on the tribological properties of a stainless steel and polymer composite material combination is studied. The significance of considering creep, friction during the stroke and contact temperature is specifically highlighted. The novel tribometer can be used to screen different bearing and shaft material combinations and to evaluate the friction and wear performance of self-lubricating bearings for the specific operating conditions found in Kaplan turbines.
\end{abstract}

Keywords: Kaplan turbine; self-lubricating; service life; lubrication; wear

\section{Introduction}

There are many moving machine assemblies (MMAs) where a high load between two contacting surfaces under relative motion is distributed over a relatively large area, giving rise to an area contact with high contact pressure. A common application is sliding bearings, but other MMA applications include marine applications (such as propeller shaft bearings), machine guideways and metalworking applications (such as forming and forging). Although the friction force is theoretically independent of the nominal contact area, there are several mechanisms that are amplified when the load is carried by a larger area. Examples include retention of wear particles and increased number of adhesive contact points (junctions).

Large-scale sliding bearings are also commonly found in hydropower plant turbines, specifically in the guide vane bearings and trunnion bearings in Kaplan turbines [1-3]. Trunnion bearings are designed for contact pressures of $40 \mathrm{MPa}$, but due to misalignments and excessive clearances, the contact pressures may reach $55 \mathrm{MPa}$ [4] or even higher (50-80 MPa) as reported by Demianov et al. [5]. In addition, sliding velocities are low $(0.001 \mathrm{~m} / \mathrm{s})$ [5] and the type of motion is oscillating. Due to environmental concerns, there is a clear trend towards removing lubricants from MMAs where potential leakage can be harmful to the environment, and hydropower plants are typical examples. Self-lubricating bearing materials are employed as alternative materials since these can be used in dry sliding or water-lubricated conditions. 
Due to the size of the bearings in these applications, full-scale tests pertaining to friction and wear performance of bearing materials are very time-consuming and inherently expensive. Therefore, laboratory tests are frequently used to evaluate the friction characteristics and wear behavior of these bearing materials. An obvious question that arises is whether the results from laboratory-scale tests can translate to full-scale bearing performance.

In order to make laboratory testing as representative of the real application as possible, the tests are required to run under relevant contact pressures, sliding velocities, temperatures and type of motion. In the case of self-lubricating polymer composite materials, the size of the test specimen plays an important role to capture all relevant material features within the intended contact area.

There are many tribological test equipment, or tribometers, available on the market today, and many of these offer the possibility to perform friction and wear tests using a flat-on-flat contact configuration and reciprocating motion [6-10]. The main limitation with these test rigs is the upper limit of contact pressure that can be reached when using an area contact. Most of the test rigs on the market have an upper normal load limit of $2500 \mathrm{~N}$, which means that for contact pressures in the range $>30 \mathrm{MPa}$ the test specimen needs to be, e.g., $9 \times 9 \mathrm{~mm}^{2}$.

Some special-purpose test equipment has also been developed by various research groups. At Uppsala University, a reciprocating flat-on-flat test setup is available [11] that can reach contact pressures $>20 \mathrm{MPa}$ at a normal load of $20 \mathrm{kN}$. The sliding velocity is limited to $4 \mathrm{~mm} / \mathrm{s}$ and the smaller test specimen is $20 \times 4.6 \mathrm{~mm}^{2}$. This allows for relevant friction and wear measurements with relatively larger test specimens but has a limitation in sliding speed. Other test rigs are developed specifically to evaluate the service life and performance of scaled-down versions of self-lubricating bearings for hydropower applications $[1,4,12]$. The full sleeve bearing test rig developed by Jones et al. $[4,12]$ is based on an oscillating vertical shaft, supported by two self-aligning rolling element bearings, onto which a stationary stainless steel sleeve is mounted. The test rig can reach a contact pressure $>20 \mathrm{MPa}$ and a speed of $\sim 9 \mathrm{~mm} / \mathrm{s}$. A similar test rig, described by Pereira et al. in [1], is capable of reaching contact pressures of $40 \mathrm{MPa}$. Another oscillating bearing test rig that enables even higher contact pressures (90 MPa) was developed by Ukonsaari et al. [13,14].

The full bearing test methods have either been developed for contact pressures lower than the maximum contact pressures seen in practice or based on typical operating conditions in a Kaplan turbine. The test specimens are also relatively large and more complex to manufacture, and hence they are more expensive compared to the simplified geometry found in commercially available tribometers. Using a shaft and bearing sleeve setup will also result in the contact pressure being difficult to control since this will depend on the bearing clearance as well as the gradual wear of the bearing surface.

Despite the vast selection of test rigs, there is still a gap in terms of the possibility to perform friction and wear tests under conditions prevalent in high contact pressure and large area contact applications such as hydropower sliding bearings. Specifically, the capacity for laboratory testing under varying stroke length, frequency and high contact pressures $(>30 \mathrm{MPa})$ is missing.

The aim of this work is therefore to develop the following:

- A novel reciprocating tribometer that can enable friction and wear tests at contact pressures up to $90 \mathrm{MPa}$ using varying stroke lengths from 0.1 to $100 \mathrm{~mm}$ and a sliding speed range from 0.1 to $100 \mathrm{~mm} / \mathrm{s}$.

- A test method to analyze the tribological performance of bearing materials using the developed test rig and furthermore demonstrate how the test method can be used to analyze the influence of contact pressure and stroke length on the friction and wear of self-lubricating polymer composite bearing materials. 


\section{Test Rig Design}

The developed test rig is based on a design where a bearing material test specimen is loaded against a countersurface positioned in a holder which has a reciprocating movement (see Figure 1). Different bearing and countersurface material combinations can thus be evaluated in terms of friction and wear which is measured during the test. In the following section, a detailed description of the test rig design is given.

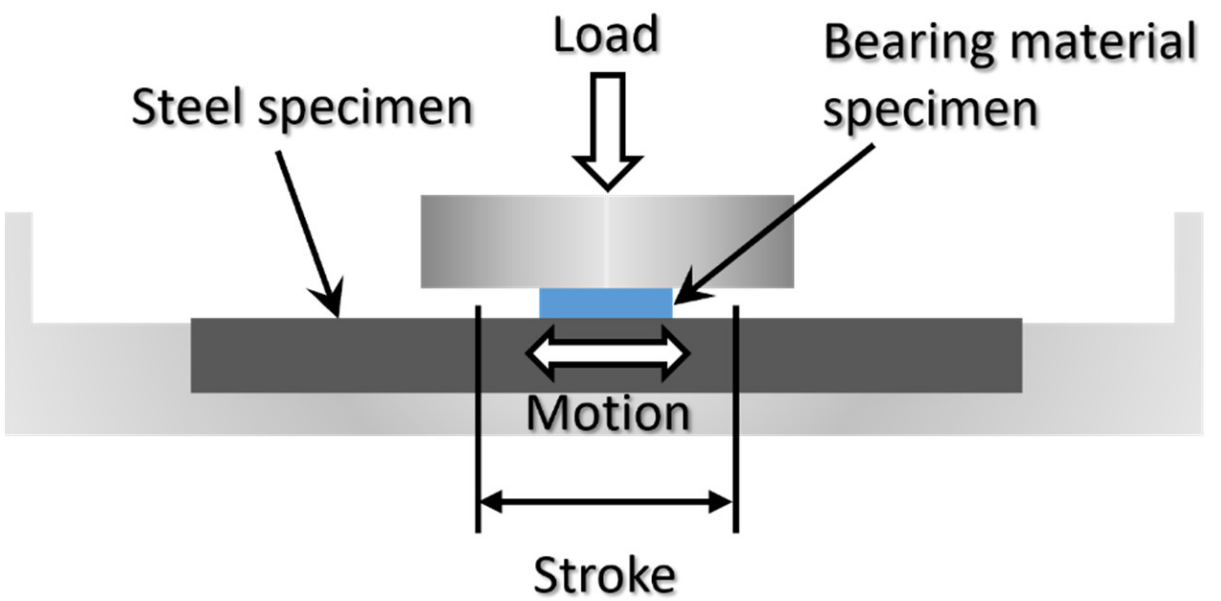

Figure 1. The operation principle of the developed test rig.

A photograph of the developed test rig can be seen in Figure 2 and an overview of the test rig can be seen in Figure 3. The normal load is applied using a pneumatic cylinder to pull a lever arm which presses a push pin (1) against a load cell (9) positioned on top of a linearly supported shaft (2) which holds the bearing material test specimen (5) (see Figure 4a). The normal load is measured with the load cell, and wear is measured using a linear variable differential transformer (LVDT) sensor (6) which senses the position of the shaft (2) relative to the stationary shaft housing (3). An electrically controlled pressure regulator (7) is used to control the normal load (see the pneumatic circuit diagram in Figure $4 \mathrm{~b}$ ). A pressure booster regulator (2) is used to increase the pressure from the pressure supply (1), and the manually operated pressure regulator (5) is used to control the input pressure to the circuit. A 4/2 directional valve (6) is used to control piston moving up or down, i.e., unload or load, and the electronic pneumatic pressure regulator (7) controls the pressure in the pneumatic cylinder (11).

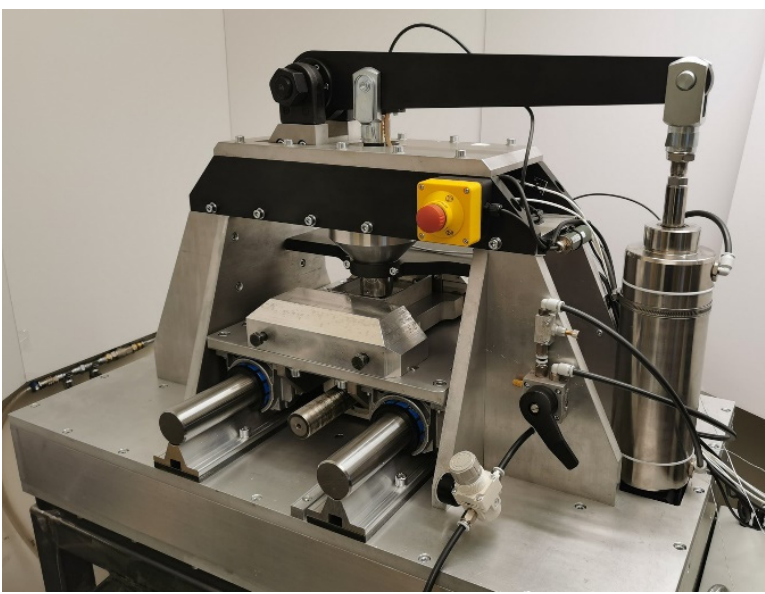

(a)

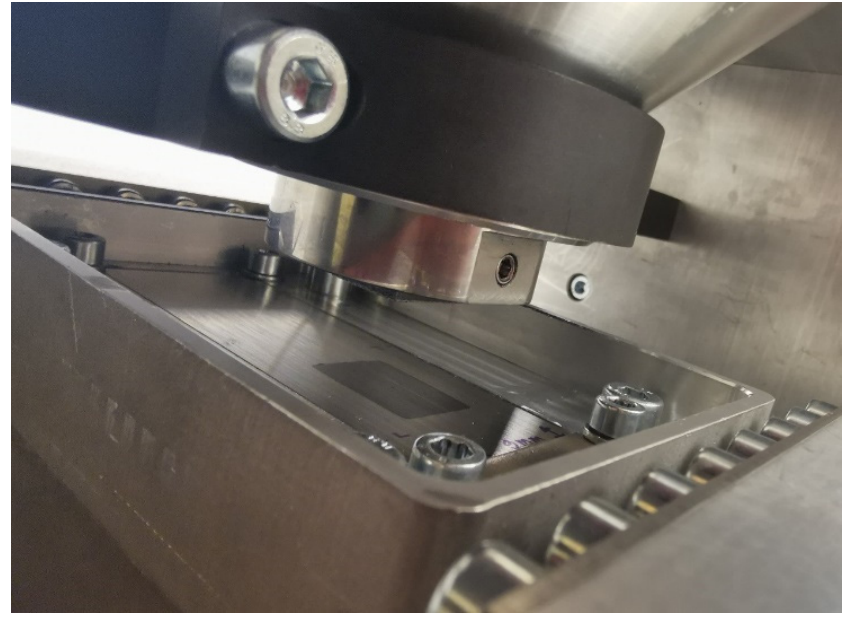

(b)

Figure 2. Photos of the developed test rig. (a) Overview of the developed test rig. (b) Close-up of the upper and lower specimen holders. 


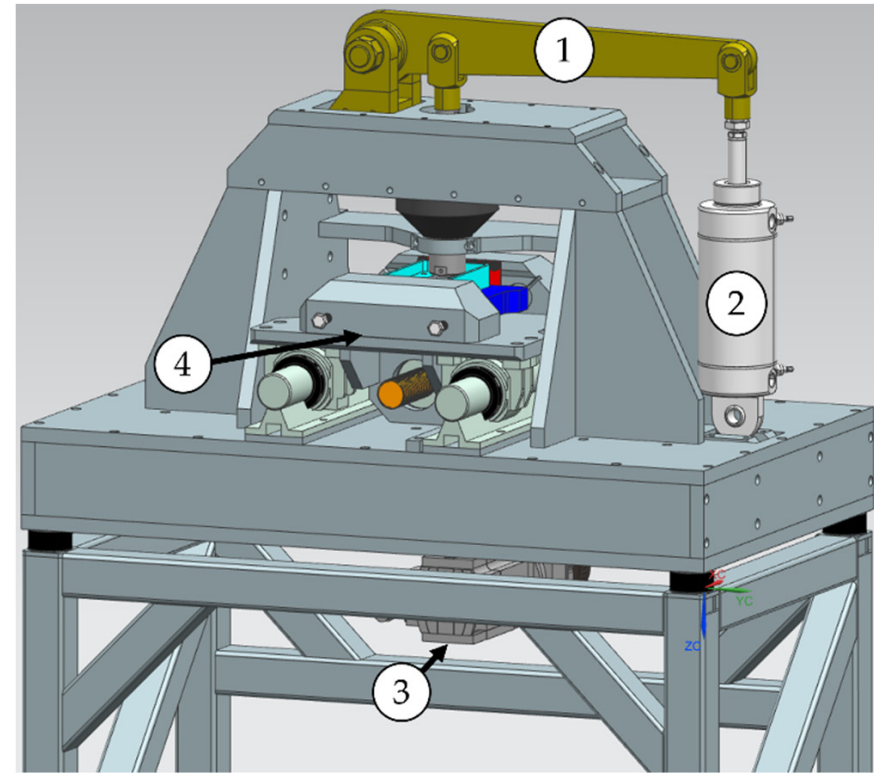

1. Lever arm

2. Pneumatic cylinder

3. Electric servo drive unit

4. Linear slide

Figure 3. Test rig overview.

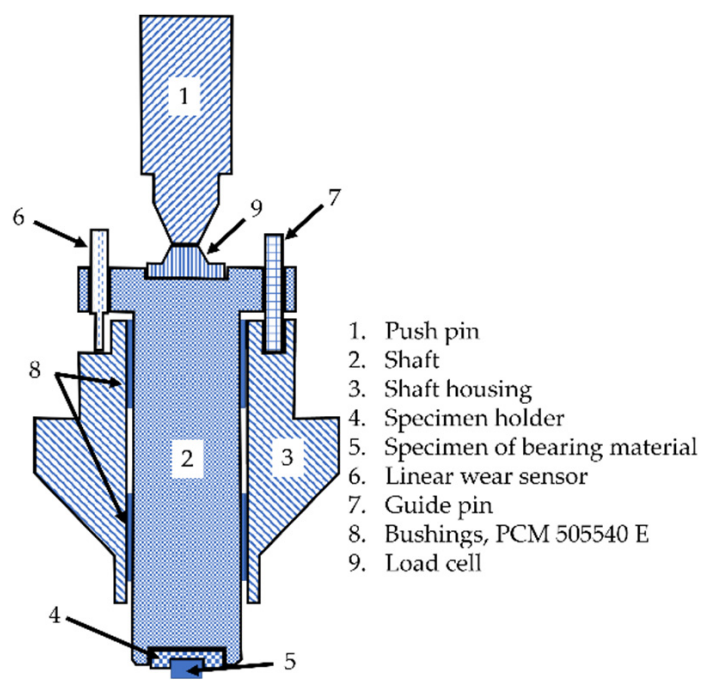

(a)

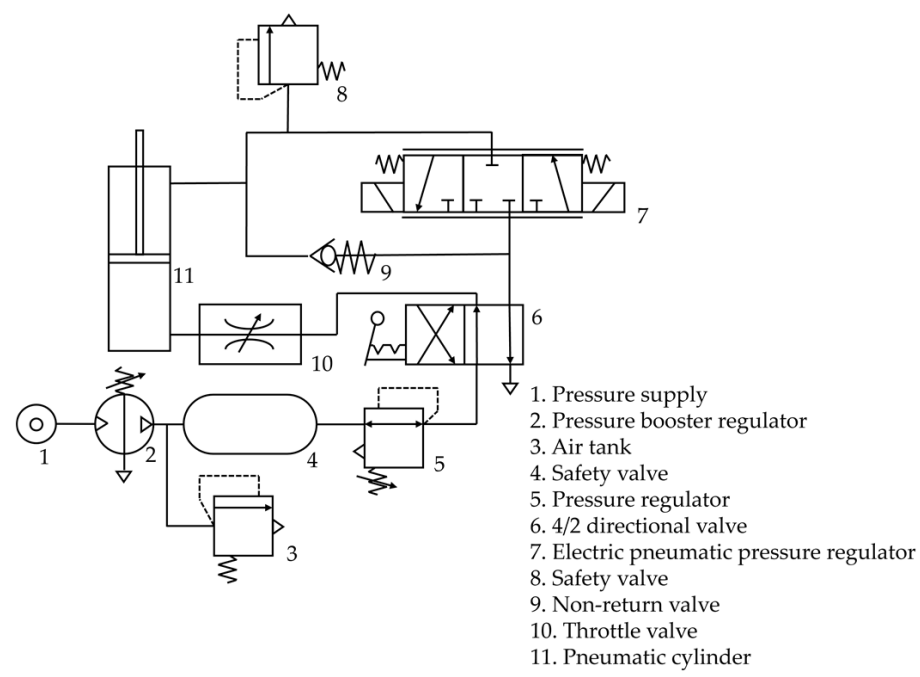

(b)

Figure 4. Normal load application system. (a) Schematic sketch of how the normal load is applied and how wear is measured. (b) Pneumatic circuit diagram of the load application system.

The reciprocating motion is enabled by the servo drive unit and transferred to the reciprocating linear slide using a belt drive with a gear ratio of 1:1. Both the upper and lower parts of the linear slide can be seen in Figure 5. The linear slide is supported by four linear guide ball bearings, and a ball screw drive, with a lead of $1.5 \mathrm{~mm} / \mathrm{rev}$, is used to convert the reciprocating rotational motion to reciprocating linear motion (Figure $5 b$ ). Specifications for the motor drive inverter used to control the servo drive unit and thus the sliding speed can be seen in Table 1. The displacement of the linear slide, measured with a laser distance sensor Baumer OADM 12U6460/S35A at different stroke lengths, is presented in Figure 6. Note that the slider is set to stand still for $0.1 \mathrm{~s}$ at the reversal points. It can be seen that for all tested stroke lengths, the slider accelerates rapidly from standstill to the given sliding velocity, which is thereafter maintained relatively constant until a rapid deceleration at the end of the stroke before it reaches the reversal point. 


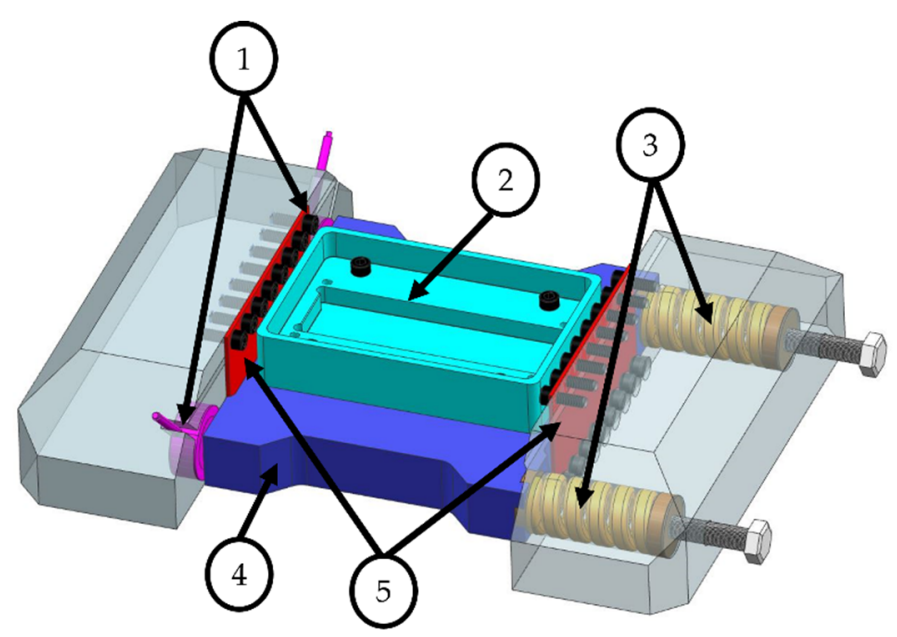

1. Load cells

2. Lower specimen holder

3. Preloaded springs

4. Base plate

5. Spring plates

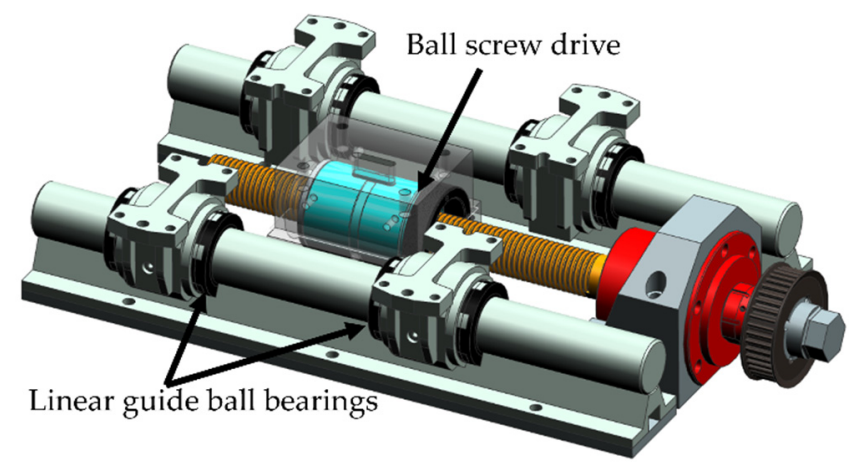

(a)

(b)

Figure 5. Linear drive unit. (a) Layout of the upper part of the linear drive unit. The picture shows the principle behind the friction load measurement. (b) Layout of the lower part of the linear drive unit.

Table 1. Data acquisition system and drive unit.

\begin{tabular}{cc}
\hline Function & Model Number \\
\hline DAQ System & NI cDAQ-9174 \\
Voltage input module & NI 9205 \\
Relay output module & NI 9485 \\
Voltage output module & NI 9263 \\
Thermocouple input module & NI 9213 \\
Motor drive inverter & MDX61B 0040-5A3-4-00 \\
Electric motor drive & CMP71M (synchronous servo motor) \\
\hline
\end{tabular}

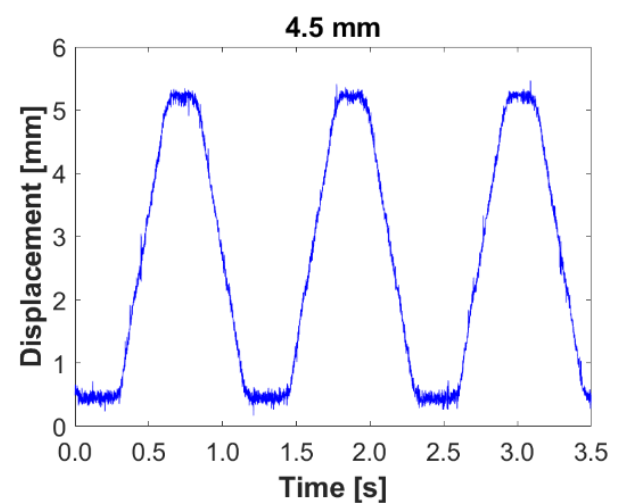

(a)

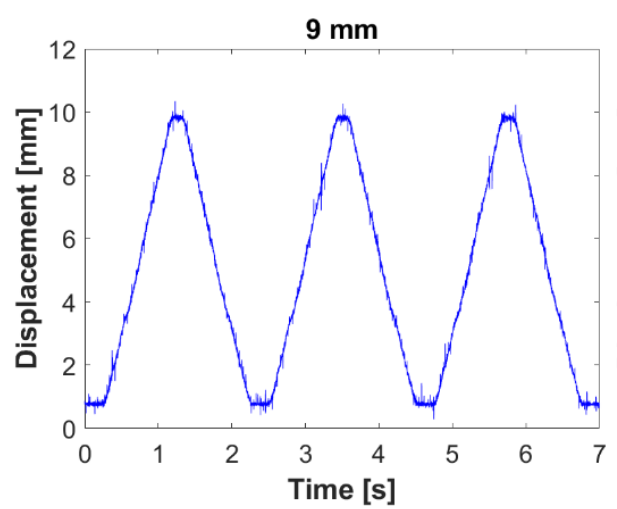

(b)

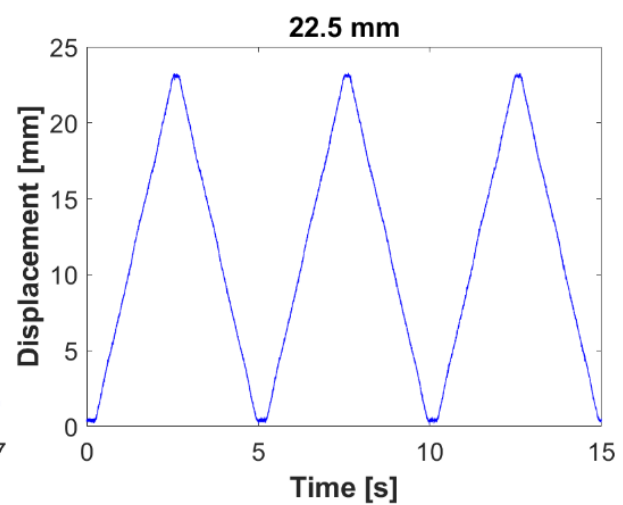

(c)

Figure 6. The displacement of the linear slide measured with a laser distance sensor at a stroke length of (a) $4.5 \mathrm{~mm}$, (b) $9 \mathrm{~mm}$ and (c) $22.5 \mathrm{~mm}$. The nominal contact pressure is $40 \mathrm{MPa}$ and the sliding velocity is $8.8 \mathrm{~mm} / \mathrm{s}$ for the stroke length of $9 \mathrm{~mm}$ and $9.5 \mathrm{~mm} / \mathrm{s}$ for stroke lengths of 4.5 and $22.5 \mathrm{~mm}$. The linear slide is set to stand still for $0.1 \mathrm{~s}$ at the reversal points. Observe that the range for the y-axis differs between the figures. The sensor has a resolution ranging between 16 and $120 \mu \mathrm{m}$ depending on the measurement distance. 
In Figure 5a the principle of the friction load measurement is shown. The lower specimen holder is fixed on top of a base plate which is suspended between two supports using two spring plates. Friction is measured using two load cells that have been preloaded to half of their capacity using two springs of high stiffness.

Normal loads of up to $30 \mathrm{kN}$ and friction forces of up to $20 \mathrm{kN}$ can be measured in the developed test rig. The specifications of the test rig seen in Table 2 have been chosen to cover the range of operating conditions in the Kaplan trunnion bearings. The sensors used in the test rig to measure friction and wear can be seen in Table 3. Tests can be performed in dry or lubricated conditions with relevant lubricant, e.g., water, grease or oil.

Table 2. Test rig operating condition specifications.

\begin{tabular}{cc}
\hline Contact Configuration & Flat-On-Flat \\
\hline Sample size of bearing material & $18 \times 18(\mathrm{~mm})$ \\
Stroke length & $0.1-100(\mathrm{~mm})$ \\
Sliding speed & $0.1-100(\mathrm{~mm} / \mathrm{s})$ \\
Maximum contact pressure & $90(\mathrm{MPa})(18 \times 18 \mathrm{~mm} \mathrm{sample} \mathrm{and} 30 \mathrm{kN}$ load $)$ \\
\hline
\end{tabular}

Table 3. Load and displacement sensors used.

\begin{tabular}{cc}
\hline Normal load cell & Burster 8526-6050 \\
Friction load cells & Burster 8526-6050 \\
LVDT displacement sensor & Burster 8739-5002-V501 \\
\hline
\end{tabular}

The data acquisition system consists of a National Instruments CompactDAQ chassis which contains the I/O modules shown in Table 1 . The analog voltage input module connected to both friction and normal load cells has a maximum sample rate of $250 \mathrm{kS} / \mathrm{s}$ and the thermocouple input module has a maximum aggregate sample rate of $75 \mathrm{~S} / \mathrm{s}$. The thermocouple module has built-in cold junction compensation which is also used for the tests. Because of the low frequency movement in the actual tests performed, a sampling frequency of $0.05 \mathrm{~Hz}$ is used to capture the wear and slow changes in the general friction level. In addition to this, a measurement file of 40,000 measurement points is captured every $400 \mathrm{~s}$ at a sampling frequency of $1 \mathrm{kHz}$ to track changes in friction characteristics for a full stroke. National Instruments LabView is used to control the test rig and record measurement data.

\section{Experimental Materials and Methods}

In the following section, the experimental materials and methods used for the tribological tests are described.

\subsection{Materials and Specimen Preparation}

Two commercially available self-lubricating polymer composite bearing materials were used for the tribological tests, one thermoset and one thermoplastic material. The thermoset (Orkot TXM Marine) (Trelleborg Sealing Solutions Rotherham, Rotherham, $\mathrm{UK}$ ) is a fabric reinforced material incorporated with $\mathrm{MoS}_{2}$ and PTFE lubricants, and it has PTFE interwoven polyester on its running surface (Figure 7a). The thermoplastic material (Thordon ThorPlas Blue) (Thordon Bearings Inc., Burlington, ON, Canada) is a homogeneous polymer blend with incorporated additives and solid lubricants such as PTFE (Figure 7b). The characteristics and a more detailed analysis of the composition and microstructure of the materials are presented in [15]. 


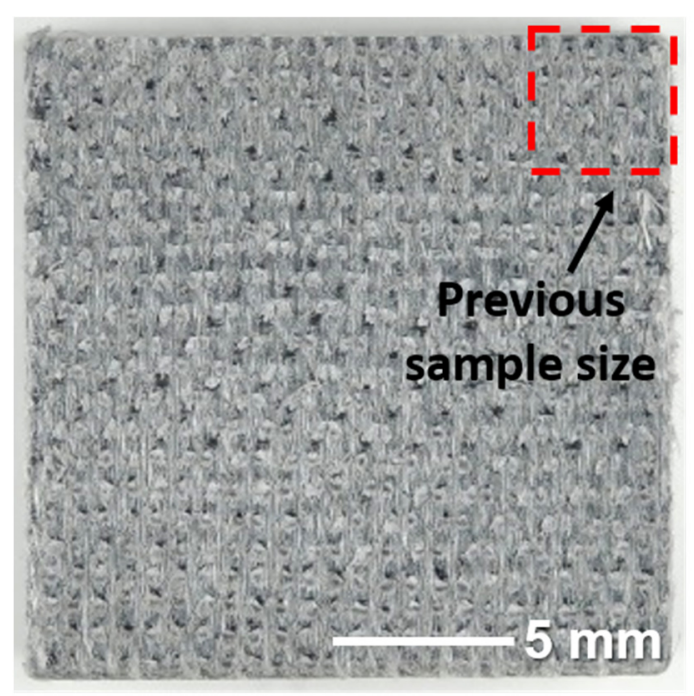

(a)

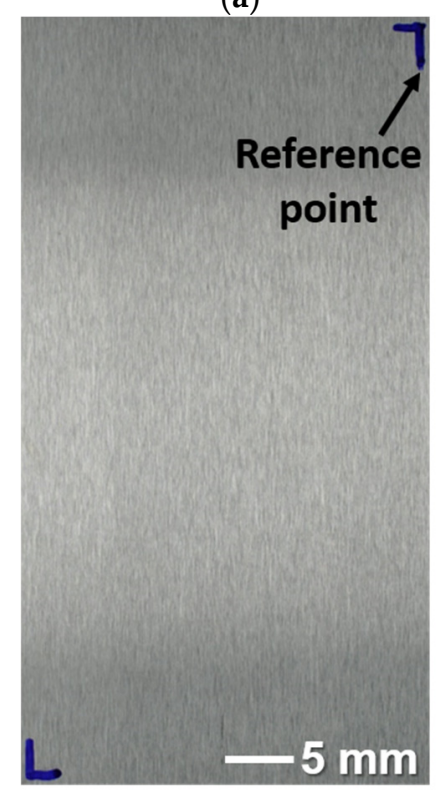

(c)

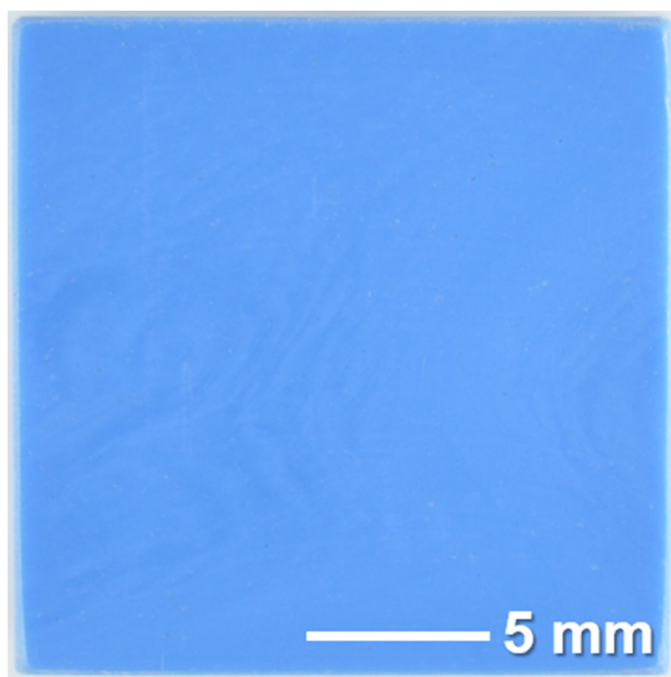

(b)

$\mathrm{mm}$

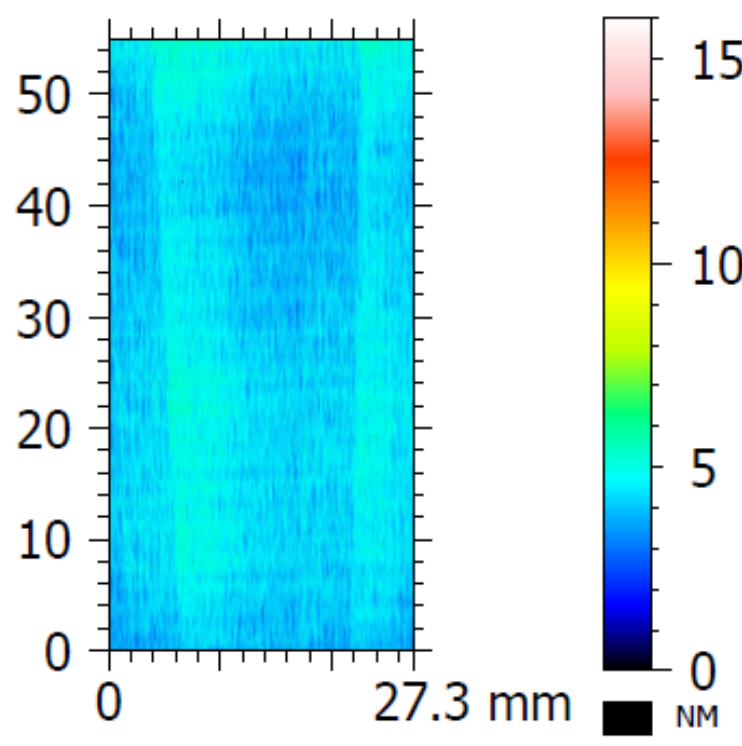

(d)

Figure 7. Representative images of the load-carrying surfaces before test of the bearing materials and stainless steel specimens used for the reciprocating tests illustrating the following: (a) thermoset pin with a marked area representing the size of the pins used in previous studies [15,16]; (b) thermoplastic pin; (c) stainless steel (SS 2333) surface with the reference points for 3D profilometry measurements; (d) surface topography of the stainless steel surface in figure (c), objective: $2.75 \times$, field of view: $0.5 \times$. The sliding direction in all figures is parallel to the vertical axis.

For the tribological tests, pin specimens with dimensions of $18 \times 18 \times 10 \mathrm{~mm}^{3}$ $(1 \times \mathrm{w} \times \mathrm{h})$ were used, machined from the two bearing materials. This gives a 20 times larger nominal contact area in comparison to previous studies by the authors $[8,15]$ where pins with dimensions of $4 \times 4 \times 4 \mathrm{~mm}^{3}(1 \times \mathrm{w} \times \mathrm{h})$ were used, illustrated in Figure 7a. In order to minimize the edge effect and to remove fibers that protrude from the surface and machining marks, the edges of the load-carrying side of the polymer pins were manually ground using $\mathrm{SiC}$ abrasive paper of grit size \#600. Thereafter, the polymer pins were cleaned in an ultrasonic bath using ethanol for three minutes and dried in air before testing. Only the thermoset polymer pins were used for studying the effect of contact pressure. For the contact temperature prediction study, thermoplastic polymer pins were used due to their homogeneous properties, which are less complex for modeling. 
Flat stainless steel plates were used as countersurfaces for the tribological tests, mounted in the lower specimen holder on the linear slide. The plates were machined to dimensions $112 \times 40 \times 10 \mathrm{~mm}^{3}(1 \times \mathrm{w} \times \mathrm{h})$ and thereafter ground with their surfaces lying parallel to the sliding direction. A representative optical image and corresponding surface topography of the SS 2333 stainless steel surface before test are shown in Figure 7c,d. Before the experiments, the plates were cleaned in an ultrasonic bath for seven minutes using ethanol and dried in air. For the study regarding the influence of contact pressure, the countersurface was made from SS 2333, which is an austenitic steel; its chemical composition is shown in Table 4. The measured hardness of the SS 2333 plates was $259 \pm 6 \mathrm{HV}_{1}$ and the areal arithmetic average surface roughness (Sa) was $0.43 \pm 0.10 \mu \mathrm{m}$. For the influence of stroke length study, the countersurface was made from SS 2387 (EN1.4418 QT 900), which is a high-strength stainless steel; its chemical composition is shown in Table 4 . The measured hardness of the SS 2387 plates was $337 \pm 7 \mathrm{HV}_{0.1}$ and the areal arithmetic average surface roughness (Sa) was $0.53 \pm 0.08 \mu \mathrm{m}$. Both stainless steel materials are corrosion-resistant and used for shafts in hydropower turbines. However, SS 2387 is more commonly used due to its higher strength.

Table 4. Chemical composition of stainless steel SS 2333 and SS 2387 in wt $\%$, Fe makes up the balance.

\begin{tabular}{ccccccccc}
\hline Stainless Steel & C & Si & Mn & P & S & Cr & Ni & Mo \\
\hline \multirow{2}{*}{ SS 2333 } & \multirow{2}{*}{ Max 0.05 } & \multirow{2}{*}{ Max 1.0 } & \multirow{2}{*}{ Max 2.0 } & Max & Max & \multirow{2}{*}{ 15.0-17.0 } & 8.0-11.0 & - \\
& & & & 0.045 & & \\
SS 2387 & \multirow{2}{*}{ Max 0.05 } & \multirow{2}{*}{ Max 1.0 } & Max 1.5 & Max & Max & $15.0-17.0$ & $4.0-6.0$ & $0.80-1.5$ \\
\hline
\end{tabular}

\subsection{Test Conditions and Methodology}

The tribological tests performed were divided into two parts: the effect of contact pressure and the effect of stroke length (see Table 5). The tribological tests were carried out using the newly developed test rig (Figure 2) under dry reciprocating sliding and ambient conditions. The test conditions are presented in Table 5, and the selected sliding speeds and contact pressures are in the range of typical operating conditions in the Kaplan turbine bearings. Two tests were carried out for each operating condition in both studies. For the effect of contact pressure study, one countersurface and one thermoset pin were used for the three contact pressures, in ascending order. A fresh countersurface and thermoset pin were used for the repetition tests. Between the wear tests, loose wear particles accumulated at the edges of the wear track, especially at the reversal points, were carefully removed using pressurized air. For the effect of stroke length study, a fresh countersurface and thermoplastic pin were used for each test.

Table 5. Experimental conditions used for the tribological tests in the two studies, i.e., effect of contact pressure and effect of stroke length.

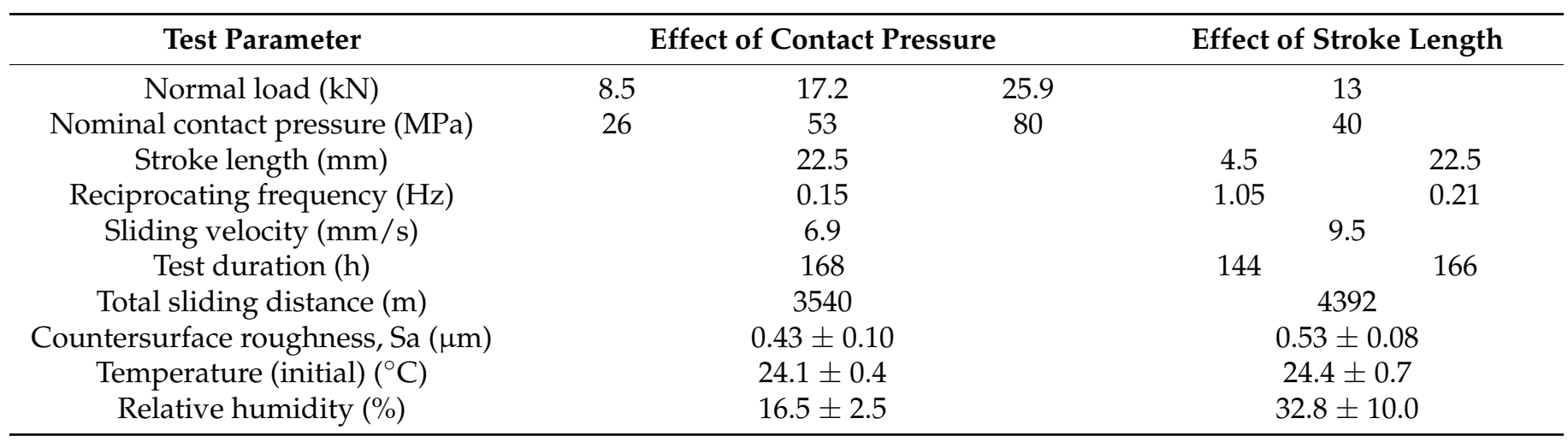


To simulate the start and stop behavior that the bearings in hydropower turbines are subjected to due to more frequent control, the slider was set to stand still for $0.1 \mathrm{~s}$ at the reversal points.

For the contact pressure study, additional static load tests were carried out to study the creep behavior of the thermoset material at the different nominal contact pressures. Two static load tests were carried out for each contact pressure where the normal load was applied for $168 \mathrm{~h}$ without reciprocating motion. Similar to the dynamic tests, one countersurface and one thermoset pin were used for the three contact pressures, in ascending order. A fresh countersurface and thermoset pin were used for the repetition tests. The creep behavior was measured by continuously monitoring the height reduction of the polymer pin using the LVDT displacement sensor.

During the tribological tests, the friction force was continuously measured by the load cells using $1 \mathrm{kHz}$ sample frequency. The friction measurements were used to calculate moving average friction coefficient values for the complete test duration. The maximum friction coefficient during one stroke and how this value varies with time were also analyzed.

The wear of the polymer pin was continuously measured using the LVDT displacement sensor, and the wear data were collected with $20 \mathrm{~s}$ intervals. The specific wear rates were calculated for the interval between $80 \mathrm{~h}$ and the end of the test based on earlier findings [4] stating that most of the commercially available polymer composite bearing materials used in hydropower applications reach a steady-state wear rate before $80 \mathrm{~h}$ of operation.

The temperature was measured using six type K thermocouples during the tribological experiments with the thermoplastic material to study how the contact temperature is affected by the stroke length under the same contact pressure and sliding speed. Two experiments were carried out per stroke length $(4.5$ and $22.5 \mathrm{~mm})$. The positions of the thermocouples are illustrated in Figure 8. Note that thermocouple number 3 is located $8.5 \mathrm{~mm}$ below number 2 to measure the difference in temperature through the depth of the steel plate. One thermocouple was located between the upper specimen holder and the right edge of the polymer pin. The ambient temperature was measured using a thermocouple located in ambient air at the same height as the contact between the polymer pin and the stainless steel plate. The thermocouple data were collected with a sample frequency of $1 \mathrm{~Hz}$.

In addition to measuring the temperature distribution in the steel disc, two different approaches to estimate the contact temperature were used. The first approach was to estimate the contact temperature in the middle of the wear track $\left(\mathrm{T}_{\mathrm{c}}\right)$ using a reformulation of Fourier's law according to the following:

$$
\mathrm{T}_{\mathrm{c}}=\frac{\Delta \mathrm{x}_{1} \mathrm{~T}_{2}-\Delta \mathrm{x}_{2} \mathrm{~T}_{1}}{\Delta \mathrm{x}_{1}-\Delta \mathrm{x}_{2}}
$$

where $\Delta \mathrm{x}_{\mathrm{i}}$ is the distance between the location of the thermocouple $i$ ( 1 or 2$)$ and the middle of the wear track, and $\mathrm{T}_{\mathrm{i}}$ is the measured temperature of thermocouple $i$.

The second approach was to develop an elementary heat transfer model in COMSOL Multiphysics. The model assumes a perfectly uniform contact pressure between the bearing and the stainless steel. Thereby, a corresponding uniform frictional shear stress distribution can be calculated using the obtained mean friction coefficient from the reciprocating sliding tests. The generated heat is calculated as the frictional shear stress over a sliding distance. Furthermore, the heat flux distribution can be calculated as the sum of the heat generated at all discretized steps in a cycle divided by the cycle time. In this simulation model, the thermal conductivity is the main material parameter; for the countersurface, made of stainless steel, a thermal conductivity of $15 \mathrm{Wm}^{-1} \mathrm{~K}^{-1}$ is used, and the surrounding aluminum block has a thermal conductivity of $238 \mathrm{Wm}^{-1} \mathrm{~K}^{-1}$. To make sure that the elementary model produces realistic results, temperature measurements were taken at four different locations on the countersurface using thermocouples; the location of these can be seen in Figure 8. Initial measurements indicated that the heat flux in the system was far 
from ideal. Therefore, a thin layer of air with thermal conductivity of $0.024 \mathrm{Wm}^{-1} \mathrm{~K}^{-1}$ and a convective heat flux on the upper surface of the counter specimen were included in the model. The thickness of the thin layer of air and the heat transfer coefficient were unknown and can therefore be used as variables that can be optimized to achieve a model that minimizes the error of the measurements. The calibrated model has an air layer thickness of $0.5 \mathrm{~mm}$ and a heat transfer coefficient of $51 \mathrm{Wm}^{-2} \mathrm{~K}^{-1}$.

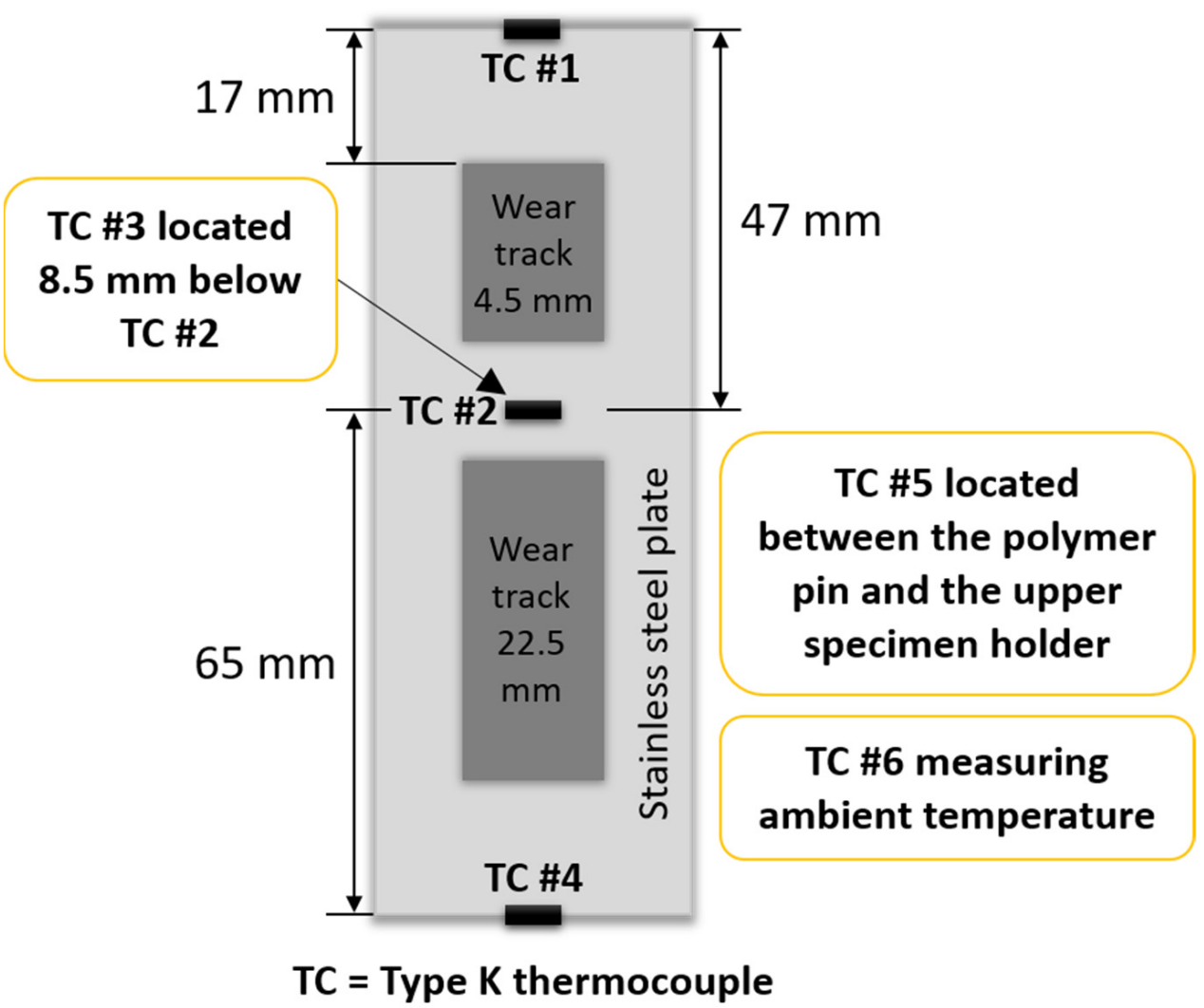

Figure 8. Schematic representation of the wear tracks on the stainless steel plate showing the positions of the six type $\mathrm{K}$ thermocouples used for measuring the temperature during the tribological tests.

Surface topography measurements of the stainless steel plate and polymer pin surface were performed using Zygo NewView 7300 (Middlefield, CT, USA) 3D optical profilometer with a $1.375 \times$ magnification for the stainless steel plates and $2.75 \times$ for the polymer pins. The before and after surface roughness measurements of the stainless steel plate were performed between the same reference points, as illustrated in Figure 7c. Optical images of the test specimens before and after the test were obtained using a digital camera Nikon D90 (Nikon, Tokyo, Japan) equipped with a Nikon AF-s 60/2,8 G ED Macro lens (Nikon, Tokyo, Japan).

\section{Results and Discussion}

In the following section, results obtained from the tribological experiments are presented and discussed.

\subsection{Repeatability of Friction and Wear Measurements}

Figure 9 shows the average and maximum coefficients of friction as a function of time for the entire test duration for the thermoset material sliding against the stainless steel at different nominal contact pressures. The enveloping curves indicate the scatter between repeat tests, and the curves for each contact pressure follow similar patterns and are close to each other. Note that the sharp peak at $113 \mathrm{~h}$ for a contact pressure of $80 \mathrm{MPa}$ was due to power failure, and the test was thereafter restarted for the remaining test duration. It is 
clear from the enveloping curves that the long-term repeatability of friction measurements for the test rig is good at all contact pressures. Both the mean and maximum coefficients of friction have a maximum deviation of $5 \%$ between repeat tests, which is within the range shown previously for the thermoset material [15-19].

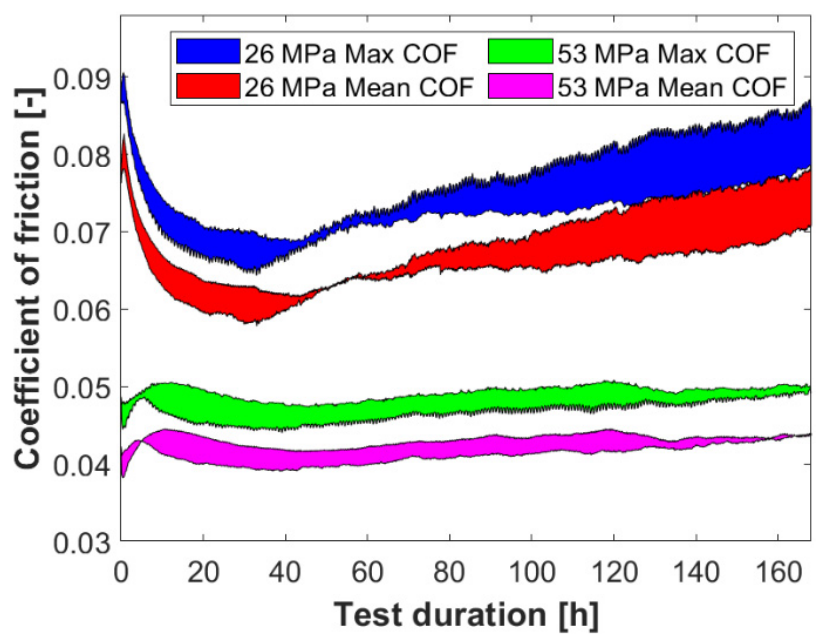

(a)

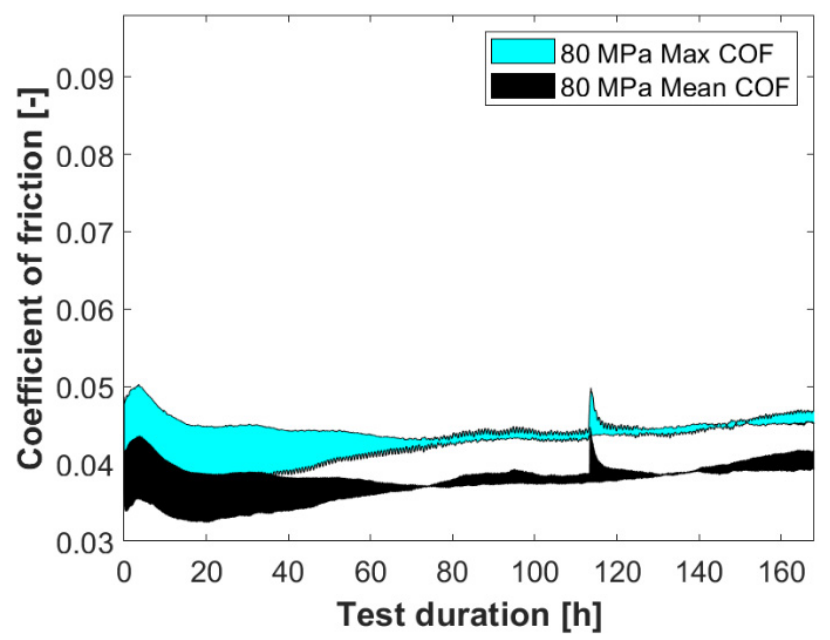

(b)

Figure 9. Average and maximum coefficients of friction versus time for the two repeat tests with the thermoset at a contact pressure of (a) 26 and $53 \mathrm{MPa}$ and (b) $80 \mathrm{MPa}$. The enveloping curves indicate the scatter between repeat tests. Note that the second test at $80 \mathrm{MPa}$ was interrupted after $113 \mathrm{~h}$ due to power failure and thereafter restarted for the remaining test duration.

The deviation in coefficient of friction between repeat tests is mainly attributed to the difference in initial countersurface roughness (Sa) between the two stainless steel countersurfaces, $0.52 \pm 0.01 \mu \mathrm{m}$ compared to $0.34 \pm 0.003 \mu \mathrm{m}$. The countersurface with the lower initial surface roughness exhibited a higher degree of abrasive wear contributing to a higher plowing component of friction. A higher coverage by transfer layers was seen for the countersurface with a higher initial surface roughness contributing a lower coefficient of friction due to improved self-lubrication. Another contributing factor for the scatter between the repeat tests is the inherent deviation between the thermoset pins due to the complex structure of the material with some variations in content and appearance as seen in Figure 7a.

Figure 10 shows the friction behavior over approximately four cycles at the end of each test $(168 \mathrm{~h})$. The friction measurements have high resolution that makes it possible to capture transient events such as the static friction peak at the beginning of the stroke.

The repeatability of the friction measurements between load cycles is very good for all tests as seen for the four load cycles in Figure 10. The same applies to the repeatability between tests, except for the $26 \mathrm{MPa}$ tests that have a slightly different appearance which is likely due to the deviation in initial surface roughness of the stainless steel countersurface and variations in the thermoset pins.

The height reduction curves of the thermoset pin as a function of time for the entire test duration at different contact pressures are presented in Figure 11. The repeat test at the contact pressure of $80 \mathrm{MPa}$ was interrupted due to power failure after approximately $113 \mathrm{~h}$ and thereafter restarted for the remaining test duration. This explains why the height reduction for the corresponding test goes to zero at the time of interruption followed by a new running-in period with a more rapid increase in height reduction, although to a lower level than the initial. The height reduction curves for each contact pressure are close to each other and follow similar trends. At low contact pressure (26 MPa), the deviation in average height reduction between repeat tests is only $1.6 \%$. The deviation increases at higher contact pressures with a maximum deviation of $9.6 \%$, which is within the range of what has previously been reported for the thermoset material $[15,18,19]$. Based on the 
height reduction curves at different contact pressures (Figure 11), it can be stated that the repeatability of the wear measurements for the test rig is good.

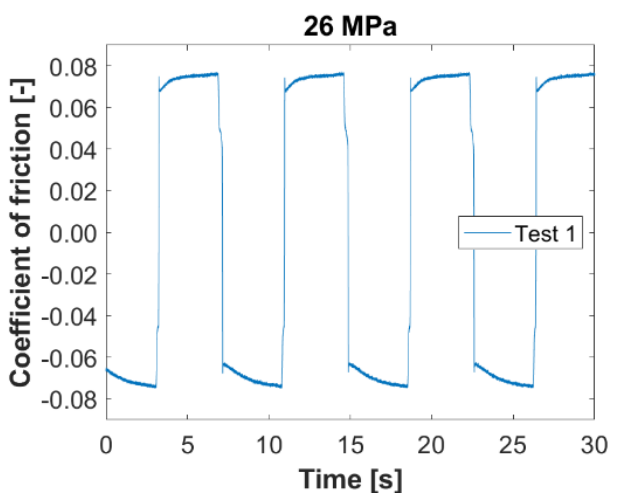

(a)

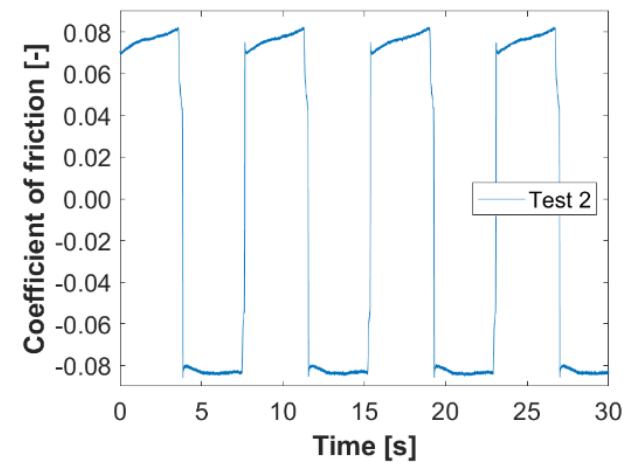

(d)

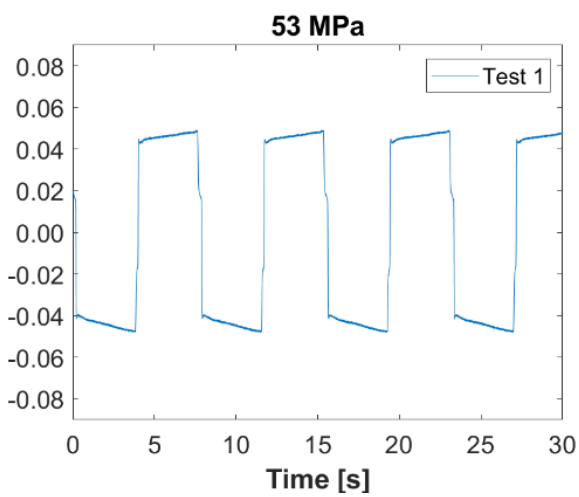

(b)

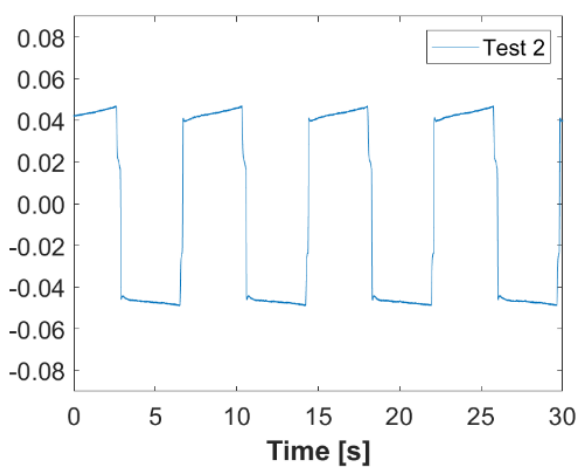

(e)

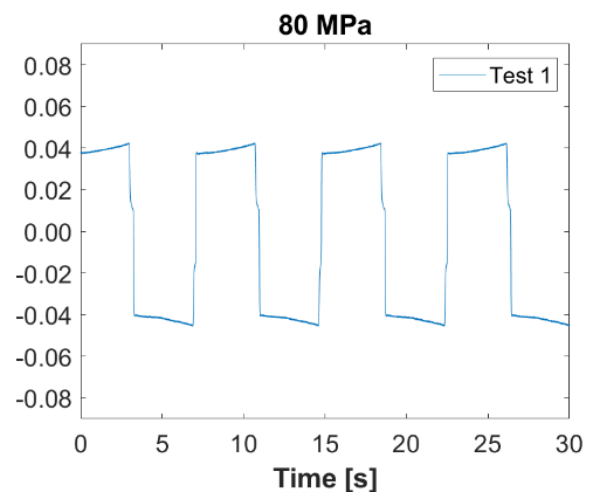

(c)

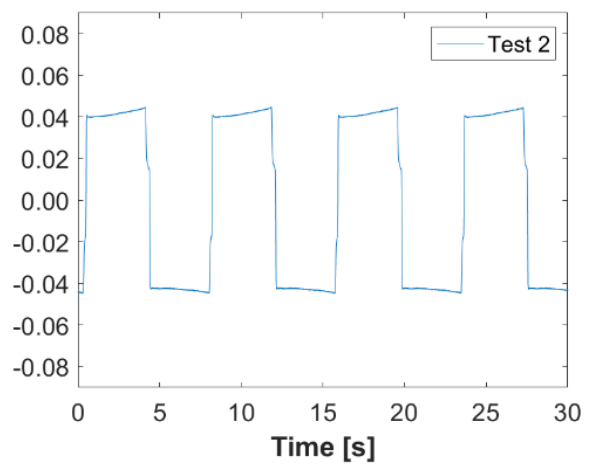

(f)

Figure 10. Coefficient of friction curves illustrating typical friction behavior at the end of the test (168 h) for the thermoset material at a nominal contact pressure of (a) $26 \mathrm{MPa}$, Test 1; (b) $53 \mathrm{MPa}$, Test 1; (c) $80 \mathrm{MPa}$, Test 1; (d) $26 \mathrm{MPa}$, Test 2 ; (e) $53 \mathrm{MPa}$, Test 2; and (f) $80 \mathrm{MPa}$, Test 2. The linear slide is set to stand still for $0.1 \mathrm{~s}$ at the reversal points.

Based on the hardness measurements reported for the thermoset material [19], a standard deviation of more than $10 \%$ can be seen between the measurements. This is attributed to the structural heterogeneity of the thermoset with nonuniform spacing between the woven fibers and larger pores situated on different locations in the material revealed by tomographic reconstruction of the material at different magnifications [15]. This is one of the explanations for the deviation in wear measurements of the thermoset between the repeat tests. The deviation is higher at higher contact pressures, where the thermoset is subjected to a higher degree of plastic deformation as exemplified in Figure 12.

\subsection{Effect of Contact Pressure on Friction and Wear}

The bearings (radial and axial) in hydropower applications operate at high nominal contact pressures up to $80 \mathrm{MPa}$ (such as the lever/link bearings). In previous studies on the thermoset bearing material, nominal contact pressures between 20 and $28 \mathrm{MPa}$ have been selected for flat-on-flat configurations using small pins with dimensions of $4 \times 4 \times 4 \mathrm{~mm}^{3}[8,15,18,19]$ and nominal contact pressures of 20-30 MPa have been selected for journal bearing configurations $[4,20,21]$. For the flat-on-flat configurations, the maximum load is limiting the nominal contact pressures and the polymer pins are usually quite small to obtain higher contact pressures. Therefore, it is of great interest to investigate the tribological behavior of polymer composite bearing materials at nominal contact pressures higher than $30 \mathrm{MPa}$ and to use larger polymer pins. 


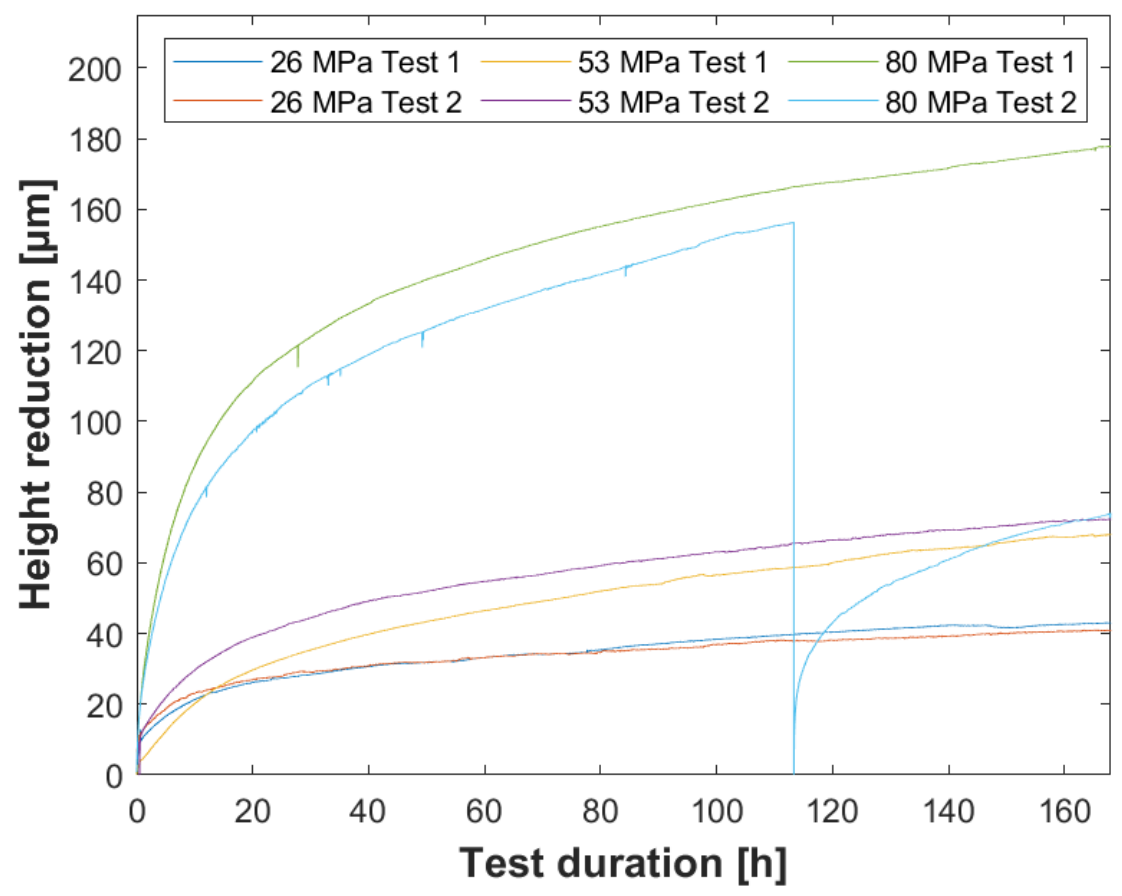

Figure 11. Height reduction versus time for the thermoset material at different nominal contact pressures. Note that the second test at $80 \mathrm{MPa}$ was interrupted after $113 \mathrm{~h}$ due to power failure and thereafter restarted for the remaining test duration.

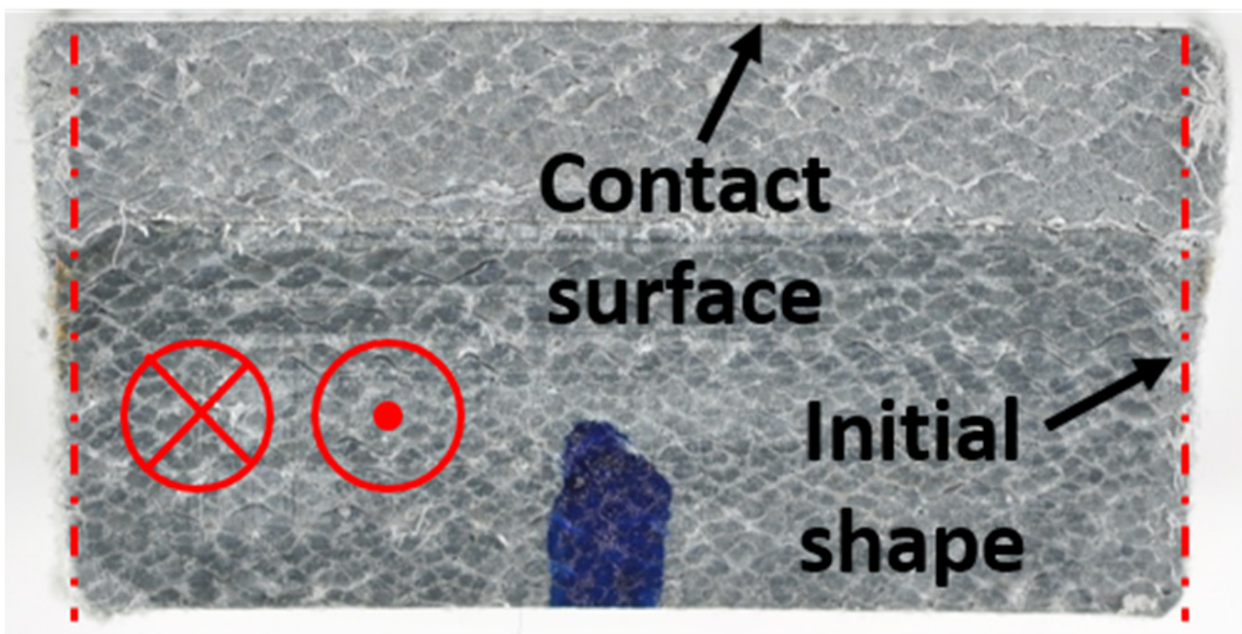

Figure 12. Optical image of the thermoset pin (side view) after sliding against the stainless steel at a contact pressure of $80 \mathrm{MPa}$. The dashed lines indicate the initial shape of the pin prior to test. Arrow symbols indicate sliding direction.

The average mean and maximum coefficients of friction for the thermoset material sliding against stainless steel at different nominal contact pressures between 26 and $80 \mathrm{MPa}$ are shown in Figure 13a. The thermoset material shows decreasing coefficients of friction, both mean and maximum, with increasing nominal contact pressure. The decrease is significantly higher between the lowest $(26 \mathrm{MPa})$ and the intermediate (53 $\mathrm{MPa})$ nominal contact pressures of $59 \%$ and $55 \%$ for the average and maximum coefficients of friction, respectively, in comparison to the difference between the intermediate and the highest $(80 \mathrm{MPa})$ nominal contact pressures of only $9 \%$ and $8 \%$, respectively. This means that the friction decrease is not following a linear trend, which has previously been reported for the thermoset material at contact pressures between 9 and $28 \mathrm{MPa}$ [15]. Instead, the rate of friction decrease slows down and stabilizes somewhere between 26 and $53 \mathrm{MPa}$. 


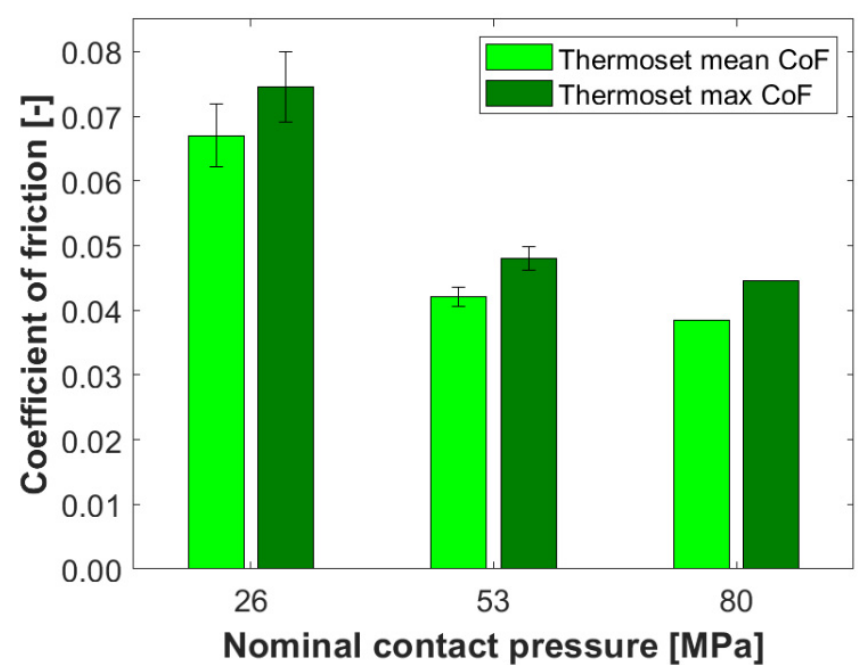

(a)

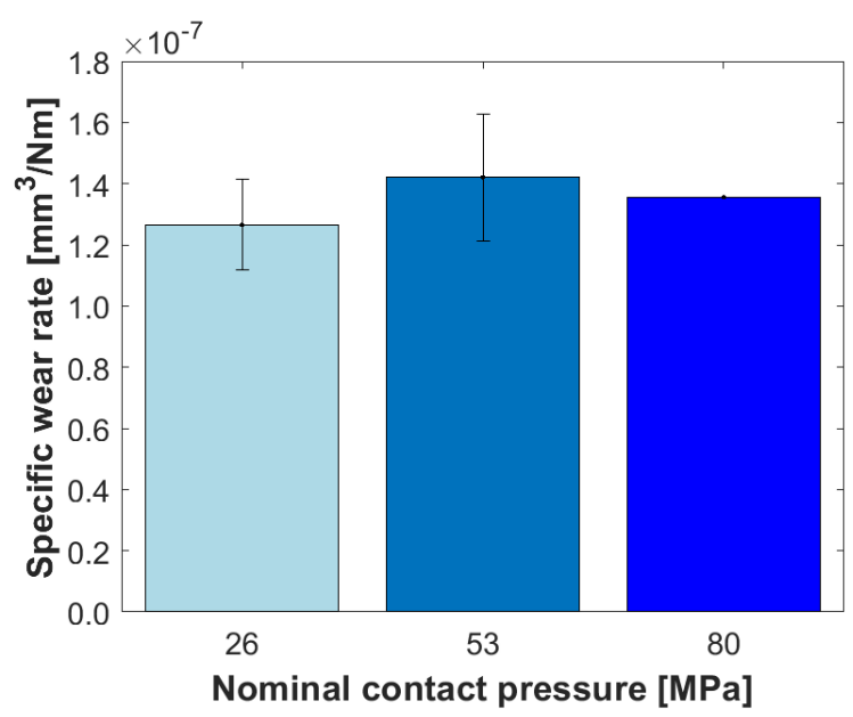

(b)

Figure 13. Variation of (a) the average of the mean and maximum coefficients of friction as a function of nominal contact pressure for the thermoset bearing material and (b) the average specific wear rate calculated between $80 \mathrm{~h}$ and the end of the test as a function of nominal contact pressure for the thermoset bearing material. Note that the standard deviation bars are missing for the reciprocating sliding tests at $80 \mathrm{MPa}$ due to interruption during the repetitive test.

The obtained mean and maximum coefficients of friction for the thermoset at the lowest contact pressure of $26 \mathrm{MPa}$, with averages of $0.067 \pm 0.005$ and $0.075 \pm 0.005$ respectively, are lower than the ones reported in previous studies at similar operating conditions $[8,15,18,19]$. This is attributed to the size of the thermoset pins used in this study, which has a 20 times larger nominal contact area in comparison to previous studies $[8,15,18,19]$. This gives a better representation of the thermoset material as seen in Figure 7a due to a proportionally higher content of solid lubricants. In addition, a larger nominal contact area is less sensitive to small misalignments and variations in surface topography of the samples.

The friction measurements of the newly developed test rig allow the study of changes in the frictional behavior over time with a high resolution. This is illustrated in Figure 14, where coefficient of friction curves over approximately half of an oscillation cycle are presented for the thermoset at $26 \mathrm{MPa}$ nominal contact pressure after $0.5,60$ and $168 \mathrm{~h}$. They represent the frictional behavior in the beginning, middle and end of the test. Friction changes over time with respect to both the behavior and the level. Hence, the friction measurements make it possible to study the frictional behavior during running-in and the steady state.

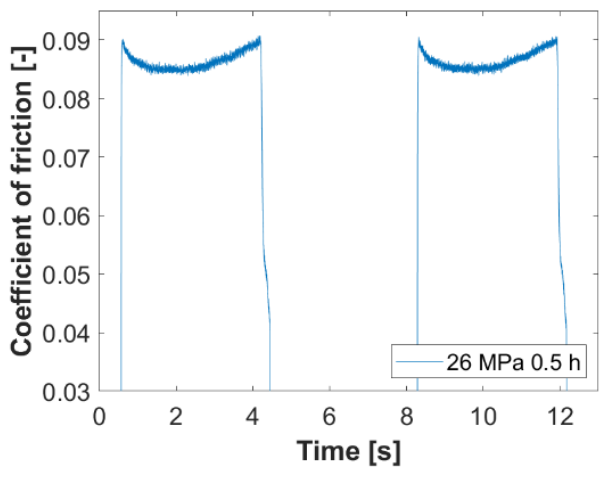

(a)

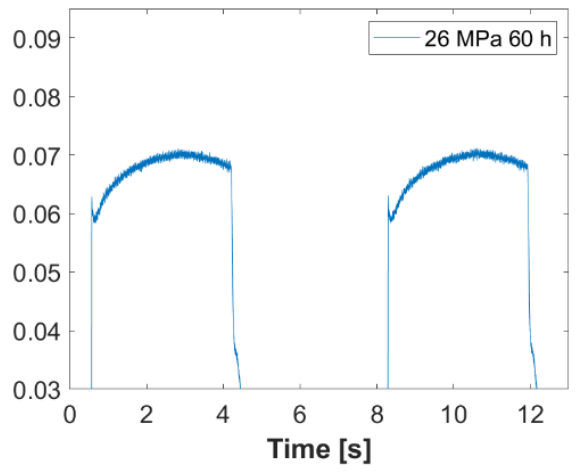

(b)

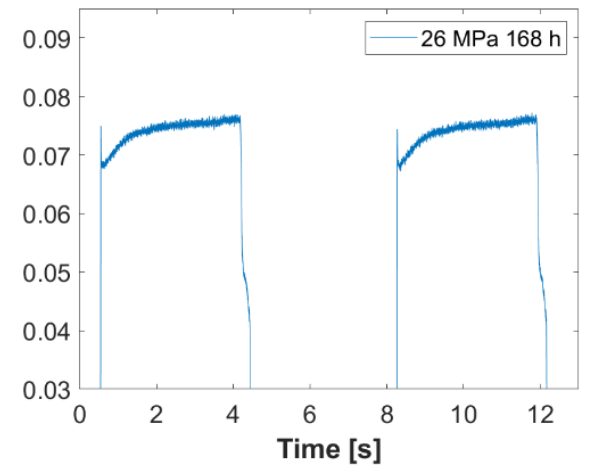

(c)

Figure 14. Coefficient of friction curves over approximately half of an oscillation cycle illustrating typical friction behavior for the thermoset with a nominal contact pressure of $26 \mathrm{MPa}$ at (a) $0.5 \mathrm{~h},(\mathbf{b}) 60 \mathrm{~h}$ and (c) $168 \mathrm{~h}$ (end of test). 
The average specific wear rates for the thermoset material sliding against stainless steel at different nominal contact pressures between 26 and $80 \mathrm{MPa}$ are presented in Figure $13 \mathrm{~b}$. In contrast to the coefficient of friction, the wear rate of the thermoset is not significantly influenced by changes in the contact pressure. The specific wear rate increases by $12 \%$ from the lowest $(26 \mathrm{MPa})$ to the intermediate $(53 \mathrm{MPa})$ nominal contact pressure where it is the highest. The decrease between the intermediate and the highest $(80 \mathrm{MPa})$ nominal contact pressure is only $5 \%$. It is interesting that despite the relatively stable wear rates, the changes in coefficient of friction are more significant between the lowest and intermediate contact pressure. A higher influence of contact pressure on the coefficient of friction compared to the specific wear rate for the thermoset has previously been reported in [15], where the highest specific wear rate was obtained at the intermediate contact pressure.

The obtained wear rate for the thermoset at the lowest contact pressure of $26 \mathrm{MPa}$, with an average of $1.27 \pm 0.15 \times 10^{-7} \mathrm{~mm}^{3} / \mathrm{Nm}$, is significantly lower than the ones reported in previous studies at similar operating conditions with an average between $3 \times 10^{-7}$ and $2.9 \times 10^{-6} \mathrm{~mm}^{3} / \mathrm{Nm}[8,15,18,19]$. This is mainly attributed to the larger thermoset pins used in this study. A larger sample means that there is a higher content of reinforcement in the material that strengthens the material and supports the load, which contributes to a higher wear resistance. This illustrates the importance of using larger thermoset pins for the tribological behavior.

The obtained wear rate at the lowest contact pressure of $26 \mathrm{MPa}$ is closer to the value reported using journal bearing set-up at similar contact pressure $(29 \mathrm{MPa})$, with an average of $0.83 \times 10^{-7} \mathrm{~mm}^{3} / \mathrm{Nm}$ [20]. This indicates that by using larger polymer pins of the thermoset material it is possible to obtain results closer to those from component testing.

The influence of contact pressure on the tribological behavior of the thermoset material has previously been studied for contact pressures between 9 and $28 \mathrm{MPa}$ [15]. The highest wear resistance was reported at the lowest contact pressure and the lowest wear resistance was reported at the intermediate contact pressure. The obtained wear rates in this study (Figure 13b) show rather stable behavior for all tested contact pressures. This indicates that the wear rate of the thermoset stabilizes somewhere around 19 to $26 \mathrm{MPa}$ and is thereafter not significantly influenced by contact pressures up to $80 \mathrm{MPa}$.

The creep behavior of the thermoset material has not previously been investigated. Rodiouchkina et al. [8] suggested that the thermoset material at high contact pressure $(26 \mathrm{MPa})$ is subjected to more creep and compressive deformation rather than wear due to low material loss in comparison to the height reduction. To investigate the creep behavior of the thermoset material, static load tests were carried out for the same test duration as the reciprocating sliding tests. The height reduction of the thermoset pin as a function of time at the different nominal contact pressures is presented in Figure 15a. It can be observed that the height reduction increases with increasing contact pressure and most rapidly in the beginning.

The deviation in height reduction between repeat tests is much higher at low contact pressures (26 and $53 \mathrm{MPa}$ ) in comparison to the highest $(80 \mathrm{MPa})$ and shows a decreasing trend with increased contact pressure. This implies that there are variations in creep and deformation resistance between the thermoset pins. These variations become less prominent at higher contact pressures, where the thermoset material is subjected to a higher degree of compressive deformation as seen in Figure 12.

The average height reduction of the thermoset pin during static loading compared to reciprocating sliding at different nominal contact pressures is shown in Figure 15b. The height reduction during static loading tests increases linearly with increasing contact pressure. The height reduction from creep and compressive deformation constitutes a large part $(35 \%$ to $59 \%)$ of the total height reduction during reciprocating sliding tests, especially at the lower contact pressures. 


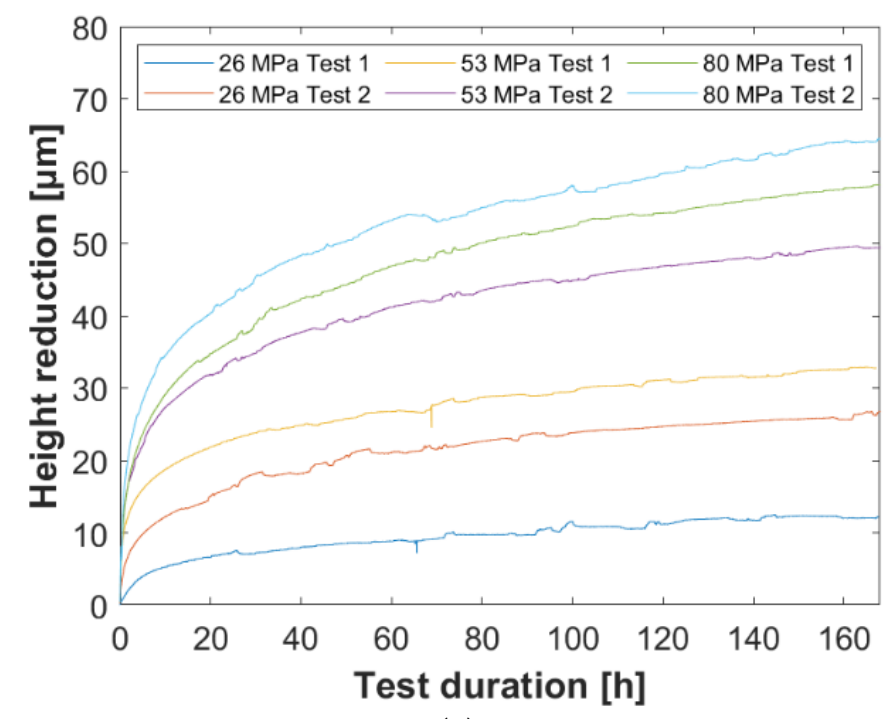

(a)

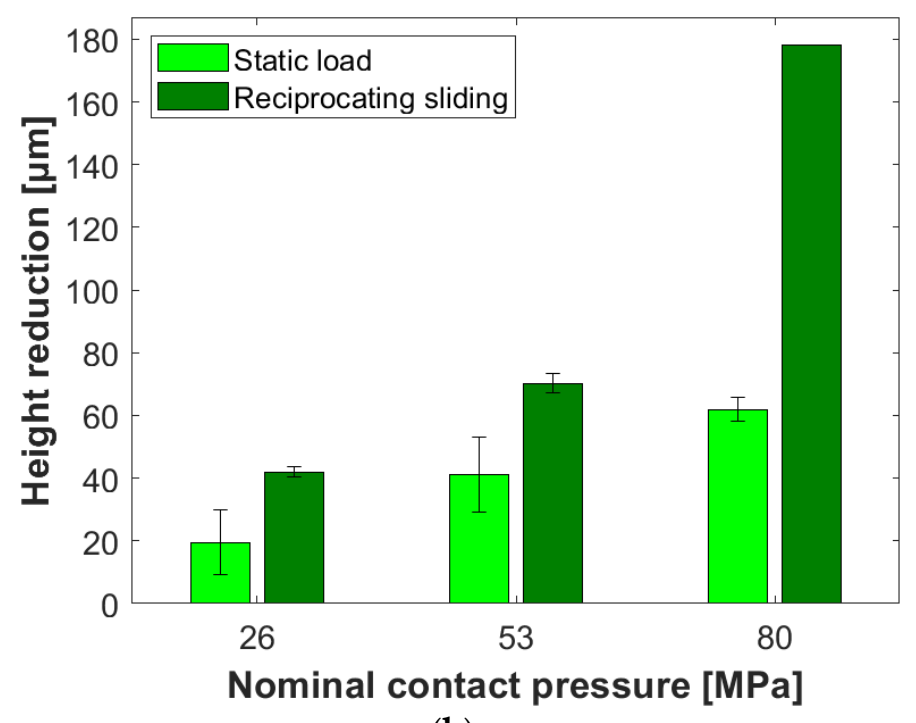

(b)

Figure 15. Variation of (a) the height reduction of the thermoset pin with test duration at different nominal contact pressures and (b) average height reduction of the thermoset pin during static loading and reciprocating sliding tests at different nominal contact pressures. Note that the standard deviation bars are missing for the reciprocating sliding tests at $80 \mathrm{MPa}$ due to interruption during the repetitive test.

The worn surface topographies of the thermoset polymer pin and the stainless steel surface are presented in Figure 16. Despite the fact that the stainless steel surface is uneven before the test (Figure $7 \mathrm{~d}$ ), the wear of the thermoset pin is evenly distributed, which is clearly visible for the lowest contact pressure of $26 \mathrm{MPa}$ (Figure 16a). This indicates a good alignment between the thermoset pin and the stainless steel surface. At higher contact pressures (53 and $80 \mathrm{MPa}$ ), the edges of the thermoset pin parallel to the sliding direction are more worn than the middle, especially at the highest contact pressure. This is explained by the deformation of the thermoset pin at higher contact pressures, where the material is bulging out on the edges as illustrated in Figure 12. This leads to a reduction in strengthening from the reinforcements in the thermoset, especially in the direction of the PTFE fibers (perpendicular to the sliding direction) which are weaker than the polyester fibers (parallel to the sliding direction). Therefore, the thermoset is less wear-resistant at the edges parallel to the sliding direction.

The deformation of the load-carrying side of the thermoset pin after sliding at the lowest contact pressure $(26 \mathrm{MPa})$ is negligible, with only a $0.6 \%$ increase in the $\mathrm{x}-$ and $\mathrm{y}$-directions. The increase is slightly higher at the intermediate contact pressure but is much higher at the highest contact pressure with $9.5 \%$ in the $x$-direction and $4.5 \%$ in the $\mathrm{y}$-direction as seen in Figure 16c. This indicates that the compressive deformation is highest in the direction of the weaker PTFE fibers. As seen in Figure 12, the thermoset pin at the highest contact pressure is significantly deformed and appears to have been loaded beyond its elastic limit. This highlights the importance of the test rig to provide high normal loads to enable investigating the tribological performance of polymer composites at its limit in terms of mechanical strength.

The decrease in coefficient of friction with increased contact pressure is explained by the increase in coverage by transfer layers on the stainless steel at higher contact pressures as seen in Figure 16d-f. The number of abrasive grooves formed on the stainless steel surface is increased at the highest contact pressure (Figure 16f) in comparison to the lower contact pressures (Figure 16d,e). This explains the lower decrease in coefficient of friction between the intermediate and highest contact pressure in comparison to between the lowest and the intermediate due to the increased plowing component of friction. 


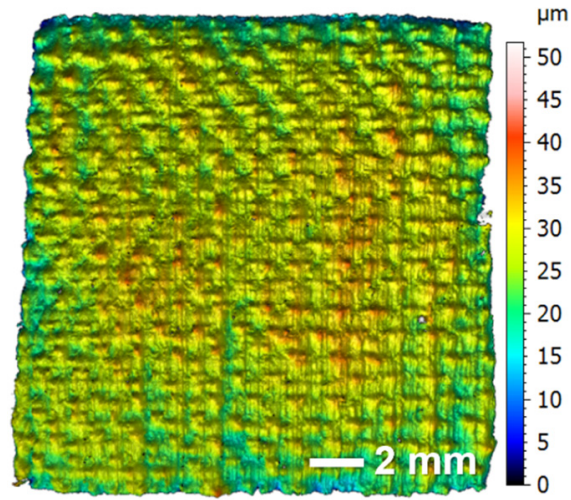

(a)

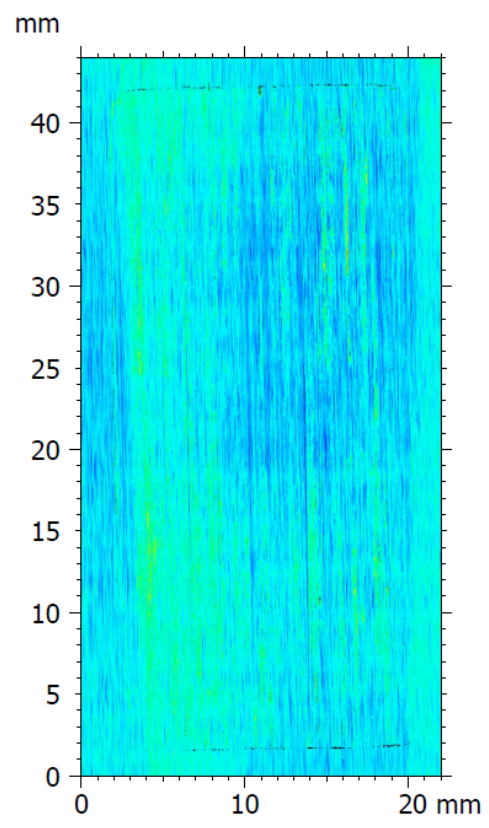

(d)

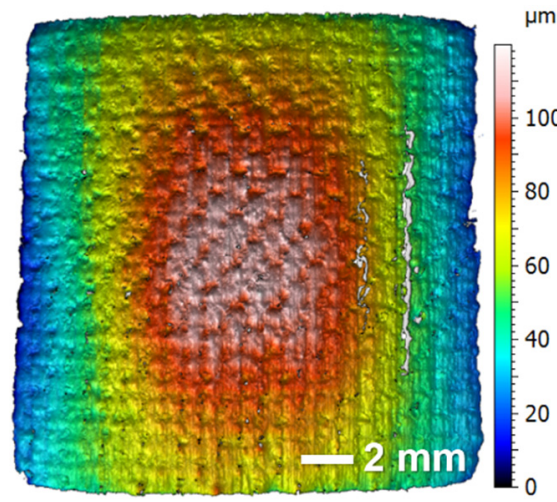

(b)

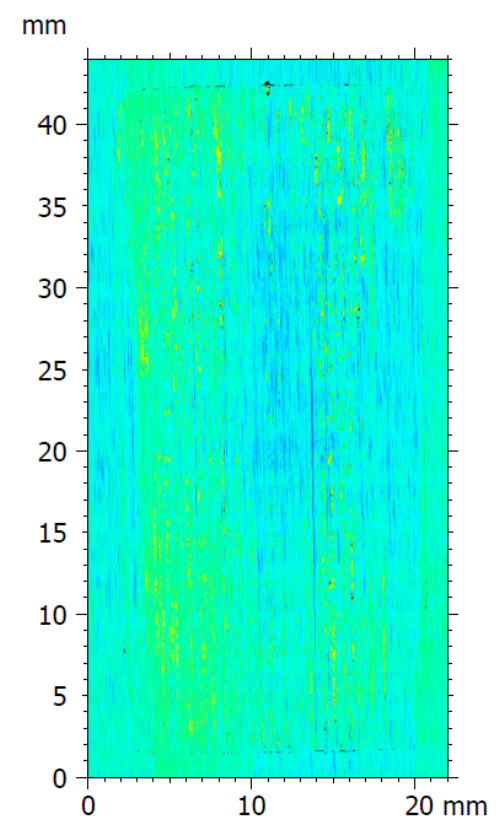

(e)

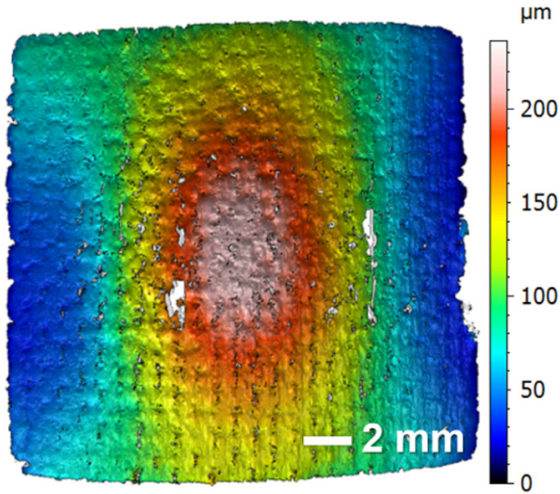

(c)

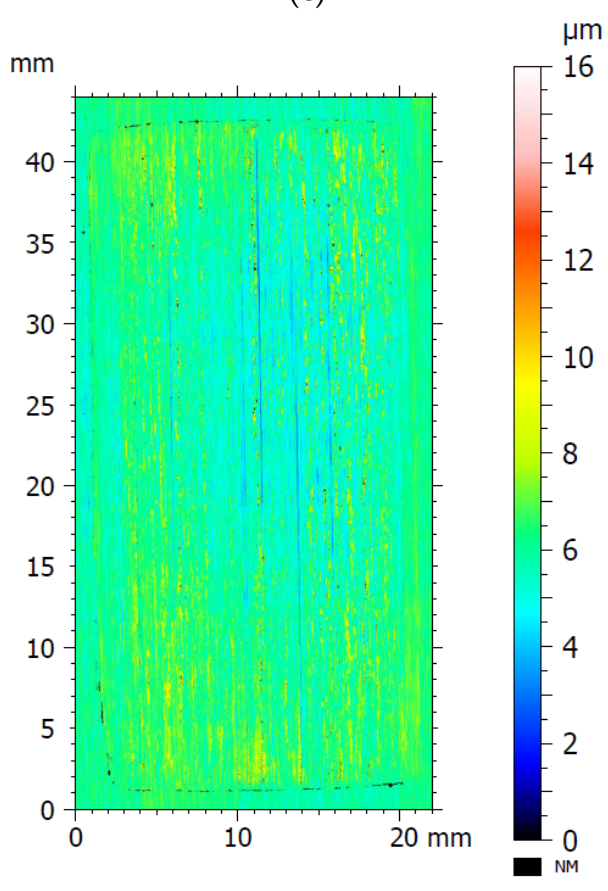

(f)

Figure 16. Surface topography of the load-carrying surface of the thermoset after sliding against stainless steel at a nominal contact pressure of (a) $26 \mathrm{MPa}$, (b) $53 \mathrm{MPa}$ and (c) $80 \mathrm{MPa}$. Objective: $2.75 \times$, field of view: $1 \times$. Observe that the scale on the $y$-axis differs between the different pressures. Surface topography of the wear track formed on the stainless steel surface after sliding against the thermoset at a nominal contact pressure of (d) $26 \mathrm{MPa}$, (e) $53 \mathrm{MPa}$ and (f) $80 \mathrm{MPa}$. Objective: $2.75 \times$, field of view: $0.5 \times$. Black areas in figure $(\mathbf{d}-\mathbf{f})$ are missing data points and correspond to regions with thick layers of polymer wear debris, which have poor reflectivity during surface topography measurements. The sliding direction in all figures is parallel to the vertical axis.

\subsection{Effect of Stroke Length and Contact Temperature Prediction}

In this section, the results for the two different approaches to estimate the contact temperature based on thermocouple measurements are shown. The average mean and maximum coefficients of friction for the thermoplastic material sliding against stainless steel at stroke lengths of 4.5 and $22.5 \mathrm{~mm}$ are shown in Figure 17. The thermoplastic material shows a slightly decreasing coefficient of friction with increasing stroke length, especially for the maximum coefficient of friction. 


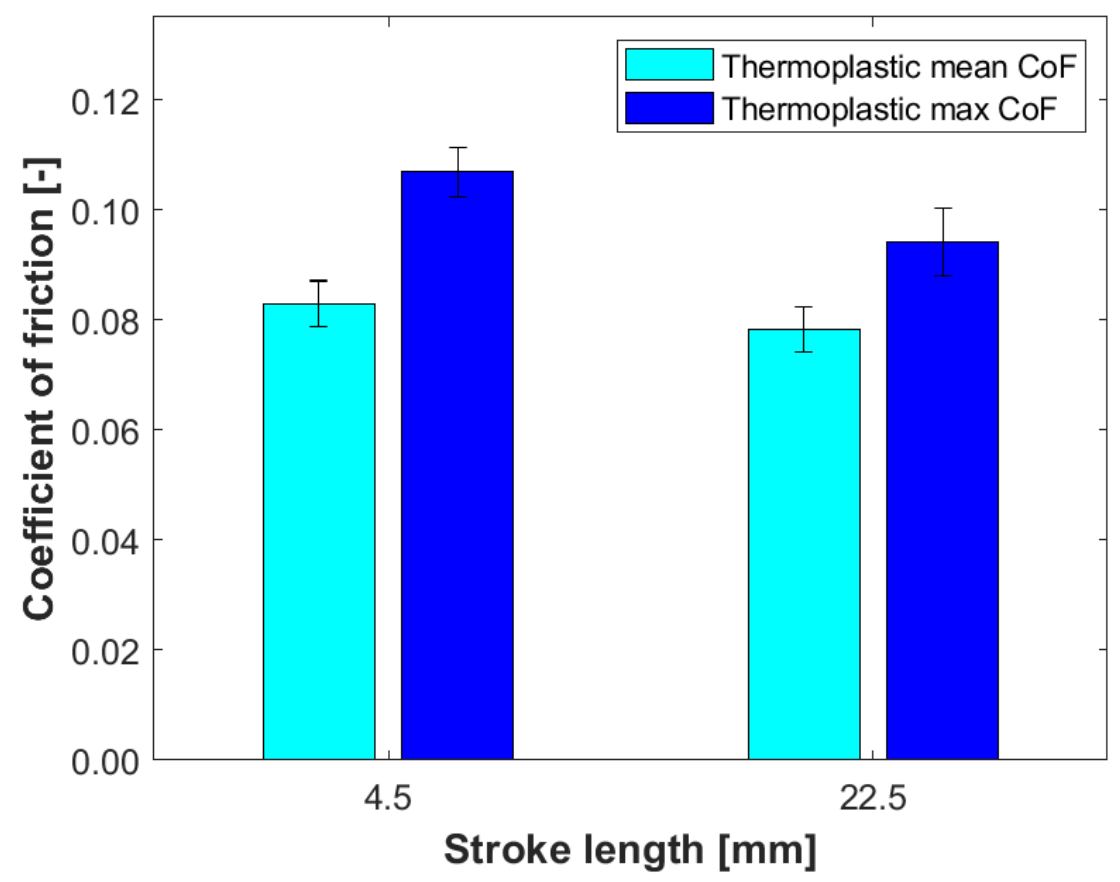

Figure 17. Average of the mean and maximum coefficients of friction as a function of stroke length for the thermoplastic bearing material.

During the tribological tests with the two stroke lengths, the temperature increase was measured using six thermocouples as illustrated in Figure 8. The two thermocouples that were closest to the wear track, i.e., numbers 1 and 2 for the $4.5 \mathrm{~mm}$ stroke length and numbers 2 and 4 for the $22.5 \mathrm{~mm}$, were used for the estimation of the contact temperature in the middle of the wear track. To study the temperature increase, the measured ambient temperature located at the same height as the contact was subtracted. The calculated contact temperature increase in the middle of the wear track as a function of time is illustrated for one test with $4.5 \mathrm{~mm}$ stroke length in Figure 18a. The corresponding mean and maximum coefficients of friction versus time for the test are shown in Figure 18b. It is clear that the contact temperature in the middle of the wear track is following similar patterns as the coefficient of friction and follows the changes in the coefficient of friction.

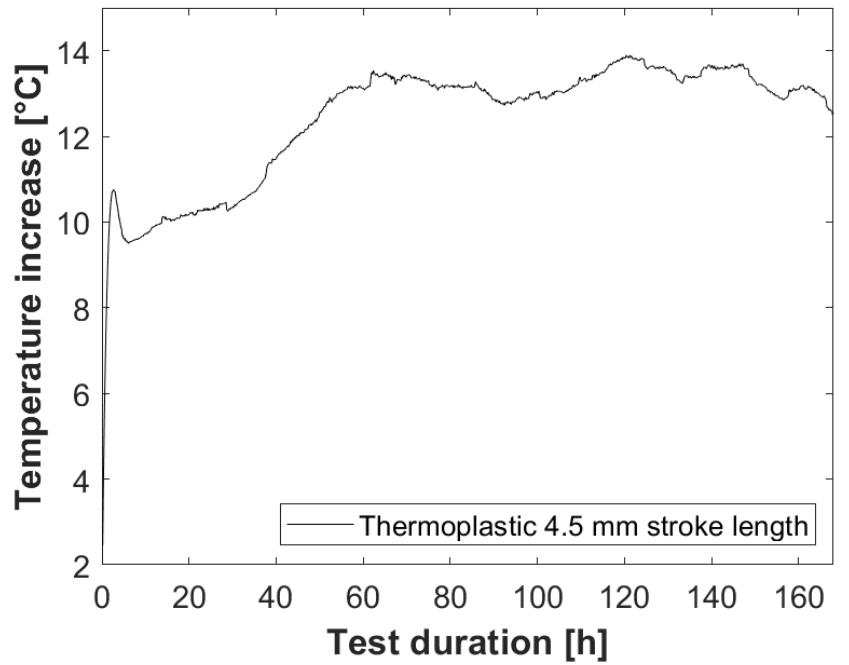

(a)

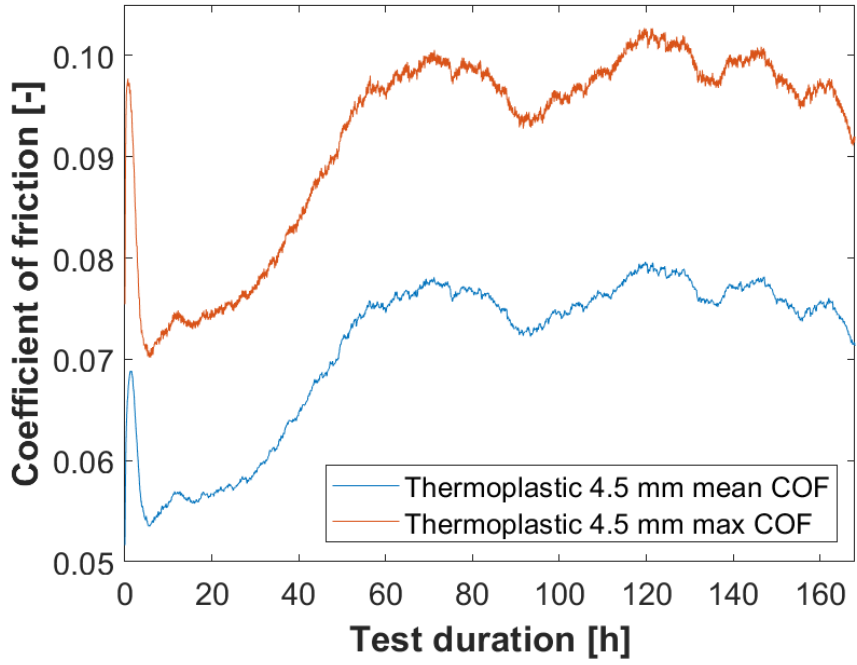

(b)

Figure 18. For the thermoplastic bearing material at a $4.5 \mathrm{~mm}$ stroke length: (a) estimated contact temperature increase in the middle of the wear track versus time; (b) the mean and maximum coefficients of friction versus time. 
The average contact temperature increase in the middle of the wear track during the steady state (after running-in period) was $13.3 \pm 0.3{ }^{\circ} \mathrm{C}$ for the $4.5 \mathrm{~mm}$ stroke length and $12.3 \pm 0.2{ }^{\circ} \mathrm{C}$ for the $22.5 \mathrm{~mm}$ stroke length. The $8 \%$ lower temperature increase at the higher stroke length is partly attributed to the lower coefficient of friction and hence the generated friction power. It is also explained by the fact that the $22.5 \mathrm{~mm}$ stroke length is longer than the thermoplastic pin $(18 \mathrm{~mm})$, which means that there will always be a part of the wear track that is exposed to the ambient environment. Hence, the stainless steel at the higher stroke length will be cooled by convection and radiation.

The temperatures measured using the thermocouples for the test presented in Figure 18 were also used to develop the contact temperature prediction model together with the measured coefficient of friction.

The elementary heat transfer simulation model was used to compare the temperature between two tests at different stroke lengths. Figure 19a shows the calibration with a $22.5 \mathrm{~mm}$ stroke length and Figure $19 \mathrm{~b}$ shows the model with a $4.5 \mathrm{~mm}$ stroke length. The friction coefficients that were used as input for the model were obtained from the reciprocating tests. The average friction values were taken at the same test duration and in the steady-state region. The $22.5 \mathrm{~mm}$ stroke length had an average coefficient of friction of 0.095 while the corresponding value for the $4.5 \mathrm{~mm}$ stroke length was 0.057 . The model shows that even though the coefficient of friction differs between the stroke lengths, the maximum average temperatures are similar (Figure 19). In contrast to the first approach to estimate the contact temperature, the elementary heat transfer model predicts temperature without any measured temperature data. Thus, the model can be used to predict and compare the average temperatures in the contact for a wide range of materials, loads, speeds, etc.

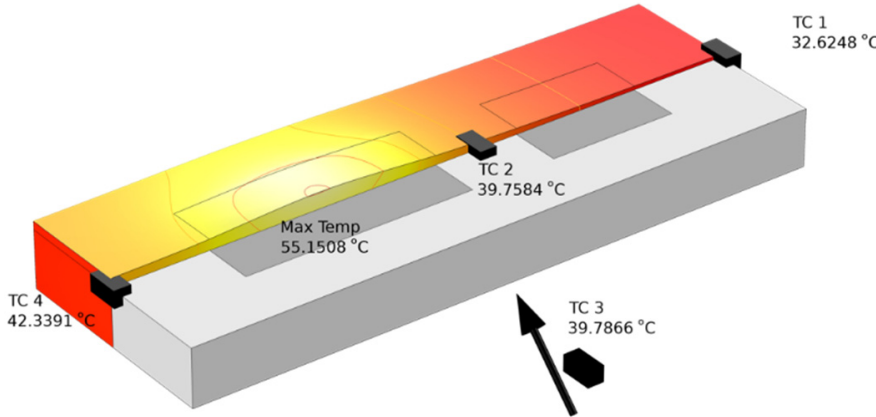

(a)

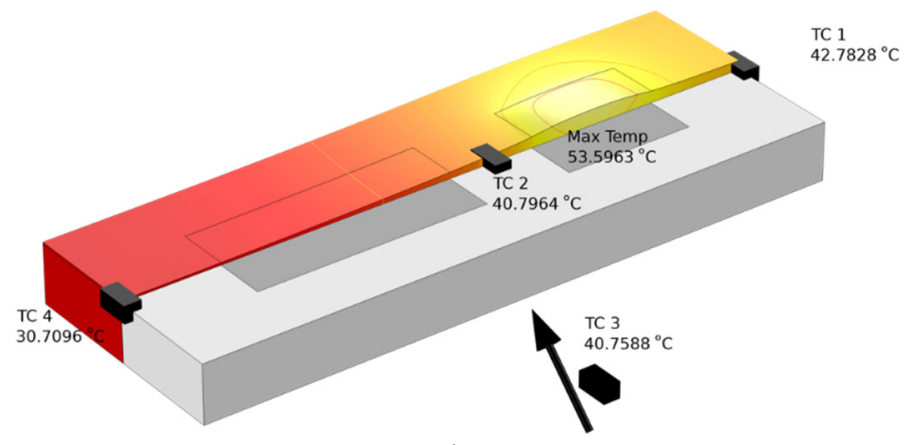

(b)

Figure 19. Illustration of the simulation model at (a) $22.5 \mathrm{~mm}$ stroke length and (b) $4.5 \mathrm{~mm}$ stroke length. The stainless steel countersurface is light gray and the wear tracks are dark gray. Black boxes indicate the location of the thermocouples, temperature distribution is shown on half the countersurface, and temperatures for the thermocouples and the maximum temperature are displayed. The black arrows point towards the position of thermocouple No. 3 which is in a milled grove underneath the stainless steel countersurface.

\section{Conclusions}

The developed test equipment and method can be used to evaluate the friction and wear performance of self-lubricating bearings for contact pressures up to $90 \mathrm{MPa}$ using varying stroke lengths from 0.1 to $100 \mathrm{~mm}$ and a sliding speed range from 0.1 to $100 \mathrm{~mm} / \mathrm{s}$. It can be used as a quick screening tool to assess the friction and wear performance of bearing material and shaft material combinations. Further, the effect of changing the operating conditions, i.e., sliding speed, contact pressure and stroke length, on the friction and wear can be characterized.

Furthermore, the developed test method considers important bearing design considerations such as the following: 
- Creep of the bearing material during static loading. The deformation due to static loading of the investigated material in this study was in the same magnitudes as wear and can be an important factor for real applications.

- Changes in the friction coefficient level during the full stroke. This is important because unfavorable changes in the frictional behavior can induce vibrations due to stick-slip in a real mechanical system.

- Contact temperature which affects the transfer film formation and thus the friction and wear properties of self-lubricating composite materials.

Author Contributions: Test rig design, main design J.J. with K.B. and M.R. as discussion partners; experimental methodology, M.R., K.B. and J.H.; test rig software, J.J.; the elementary heat transfer model was developed by K.K. All authors have read and agreed to the published version of the manuscript.

Funding: This research was funded by the Swedish hydropower centre and the Kempe foundation. The Swedish hydropower centre is funded by the Swedish energy agency — grant number 45313-1, Energiforsk, Svenska kraftnät and the collaborating universities. The APC was funded by the Swedish hydropower centre.

Data Availability Statement: The data presented in this study are available on request from the corresponding author.

Acknowledgments: The research presented was carried out as a part of Swedish Hydropower Centre (SVC). SVC was established by the Swedish Energy Agency, Energiforsk and Svenska Kraftnät together with Luleå University of Technology, KTH Royal Institute of Technology, Chalmers University of Technology and Uppsala University. We would also like to thank the Kempe Foundation for help in funding the test rig. The authors would like to thank the bearing manufacturers Trelleborg Sealing Solutions Rotherham (Rotherham, UK) and Thordon Bearings Inc. (Burlington, ON, Canada) for supplying the polymer bearing materials for the tribological tests. We would like to thank Per Gren for the equipment and assistance with the measurements of the displacement of the linear slide. We would also like to thank Roine Nilsson at Uniper for supplying the stainless steel plates and for the technical support.

Conflicts of Interest: The authors declare no conflict of interest.

\section{References}

1. Pereira, P.; Schmitt, P.; Riahi, K.; Muller-Brodmann, M. Application of self-lubricating bearings in Kaplan runner hubs. Int. J. Hydropower Dams. 2009, 16, 94.

2. Värlind, K.-E.; Leonsson, S.; Videhult, S. Environmentally adapted technology for Kaplan runners. Int. J. Hydropower Dams. 2004, $11,48-52$.

3. Lindsjo, H. Oil-free hubs spare hydro's blushes. Int. Water Power Dam Constr. 1999, 51, 19-21.

4. Jones, J.A.; Palylyk, R.A.; Willis, P.; Weber, R. Greaseless Bushings for Hydropower Applications: Program, Testing, and Results; PN: Portland, OR, USA, 1999.

5. Demianov, V.A.; Pylev, I.M.; Ilin, S.Y.; Morkin, O.V.; Chermin, A.V. Investigation of the friction materials for the adjustable blade journal bearings of the ecologically clean runner of the Kaplan turbine. In Proceedings of the Hydro 2013-Promoting the Versatile Role of Hydro, Innsbruck, Austria, 7-9 October 2013.

6. Zhao, W.; Zhao, W.; Huang, Z.; Liu, G.; Wu, B. Tribological performances of epoxy resin composite coatings using hexagonal boron nitride and cubic boron nitride nanoparticles as additives. Chem. Phys. Lett. 2019, 732, 136646. [CrossRef]

7. Ozdemir, C.A.R.; Hacioglu, B.; Kasapoglu, E.; Balakumar, R.; Sriram, G.; Arumugam, S. Assessment on Tribological Characteristics of Waste Ayurvedic Oil Biodiesel Blends using High-Frequency Reciprocating Rig Tribometer. In Proceedings of the IOP Conference Series: Materials Science and Engineering, Tamilnadu, India, 8-9 March 2018; Volume 390, p. 012047. [CrossRef]

8. Rodiouchkina, M.; Lind, J.; Pelcastre, L.; Berglund, K.; Rudolphi, Å.K.; Hardell, J. Tribological behaviour and transfer layer development of self-lubricating polymer composite bearing materials under long duration dry sliding against stainless steel. Wear 2021, 484-485, 204027. [CrossRef]

9. Meng, Z.; Wang, Y.; Xin, X.; Liu, H.; Yan, Y.; Yan, F. Enhanced fretting wear performance of UHMWPE composites by grafting Co-Ni layered double hydroxides on attapulgite nanofibers. Tribol. Int. 2021, 153, 106628. [CrossRef]

10. Siddaiah, A.; Kasar, A.K.; Khosla, V.; Menezes, P.L. In-Situ Fretting Wear Analysis of Electrical Connectors for Real System Applications. J. Manuf. Mater. Process. 2019, 3, 47. [CrossRef]

11. Tribotesting Equipment at Uppsala University (Webpage). Available online: https:/ / materialvetenskap.uu.se/applied-materialsscience/research-groups/Tribomaterials/tribotest/equipment/ (accessed on 5 October 2021). 
12. Jones, J.A. Development of a rating system for the selection of greaseless bushings. In Proceedings of the International Conference on Hydropower-Waterpower, Atlanta, GA, USA, 5-8 August 1997; pp. 1124-1133.

13. Ukonsaari, J. Tribology of Journal Bearings under Environmentally Adapted Lubrication with Shaft Oscillation. Ph.D. Thesis, Lulea University of Technology, Lulea, Sweden, 2004.

14. Ukonsaari, J.; Kassfeldt, E. Friction and wear in a conformal conjunction subjected to boundary lubrication with environmentally adapted oils. Tribol. Ser. 2002, 40, 167-172.

15. Rodiouchkina, M.; Berglund, K.; Mouzon, J.; Forsberg, F.; Shah, F.U.; Rodushkin, I.; Larsson, R. Material Characterization and Influence of Sliding Speed and Pressure on Friction and Wear Behavior of Self-Lubricating Bearing Materials for Hydropower Applications. Lubricants 2018, 6, 39. [CrossRef]

16. Andó, M.; Sukumaran, J. Tribological behavior of composite-steel on rolling/sliding contacts for various loads. In Sustainable Construction and Design; van Wittenberghe, J., Ed.; Ghent University, Laboratory Soete: Ghent, Belgium, 2011; pp. 29-34.

17. Sukumaran, J.; Andó, M.; Fereira, V.R.; de Baets, P. Effect of velocity on roll/slip for low and high load conditions in polymer composite. In Sustainable Construction and Design; van Wittenberghe, J., Ed.; Ghent University, Laboratory Soete: Ghent, Belgium, 2011; pp. 122-127.

18. Berglund, K.; Shi, Y. Friction and Wear of Self-Lubricating Materials for Hydropower Applications under Different Lubricating Conditions. Lubricants 2017, 5, 24. [CrossRef]

19. Somberg, J.; Saravanan, P.; Vadivel, H.S.; Berglund, K.; Shi, Y.; Ukonsaari, J.; Emami, N. Tribological characterisation of polymer composites for hydropower bearings: Experimentally developed versus commercial materials. Tribol. Int. 2021, $162,107101$. [CrossRef]

20. Gawarkiewicz, R.; Wasilczuk, M. Wear measurements of self-lubricating bearing materials in small oscillatory movement. Wear 2007, 263, 458-462. [CrossRef]

21. Ukonsaari, J. An Oscillating Steel Shaft Loaded on Lubricated Journal Bearings with Water and An Environmentally Adapted Lubricant (EAL); IAHR Symposium on Hydraulic Machinery and Systems: Stockholm, Sweden, 2004. 